Peer Reviewed Article openaccess

\title{
Prospective study for commercial and low-cost hyperspectral imaging systems to evaluate thermal tissue effect on bovine liver samples
}

\author{
Mohamed Hisham Aref,,,* Abou-Bakr M. Youssef, \\ Abdallah Abdelkader Hussein, ${ }^{c}$ Paola Saccomandid and Yasser H. El-Sharkawye \\ aBiomedical Engineering Researcher, Egyptian armed forces, Cairo, Egypt \\ bSystem \& Biomedical Engineering Department, Cairo University, Giza, Egypt \\ "Histopathology Department, "Kobri El-Koba" Complex Hospital, Egyptian Armed Forces, Cairo, Egypt \\ ${ }^{\mathrm{a} D e p a r t m e n t}$ of Mechanical Engineering, Politecnico di Milano, Milan, Italy \\ eHead of Postgraduate Studies Affairs, Military Technical College, Cairo, Egypt \\ Contacts \\ Mohamed Aref: mh-aref@ieee.org \\ (1) https://orcid.org/0000-0002-7445-3040 \\ Abou-Bakr Youssef: aboubakryoussef51@gmail.com \\ Ibrahim Aboughaleb: ehe43@hotmail.com \\ (1) https://orcid.org/0000-0001-7847-4984 \\ Abdallah Hussein: abdallahabdelkaderhussein@gmail.com \\ Paola Saccomandi: paola.saccomandi@polimi.it \\ Oittps://orcid.org/0000-0003-4236-8033 \\ Yasser El-Sharkawy: yhmelsharkawy@mtc.edu.eg \\ (1) https://orcid.org/0000-0002-0551-7282
}

Amr Sharawi: amrarsha@gmail.com

(1) https://orcid.org/0000-0001-9295-9451

Thermal ablation modalities, for example radiofrequency ablation (RFA) and microwave ablation, are intended to prompt controlled tumour removal by raising tissue temperature. However, monitoring the size of the resulting tissue damage during the thermal removal procedures is a challenging task. The objective of this study was to evaluate the observation of RFA on an ex vivo liver sample with both a commercial and a lowcost system to distinguish between the normal and the ablated regions as well as the thermally affected regions. RFA trials were conducted on five different ex vivo normal bovine samples and monitored initially by a custom hyperspectral (HS) camera to measure the diffuse reflectance ( $\left.R_{d}\right)$ utilising a polychromatic light source (tungsten halogen lamp) within the spectral range 348-950 nm. Next, the light source was replaced with monochromatic LEDs $(415,565$ and $660 \mathrm{~nm})$ and a commercial charge-coupled device (CCD) camera was used instead of the HS camera. The system algorithm comprises image enhancement (normalisation and moving average filter) and image segmentation with K-means clustering, combining spectral and spatial information to assess the variable responses to polychromatic light and monochromatic LEDs to highlight the differences in the $R_{d}$ properties of thermally affected/normal tissue regions. The measured spectral signatures of the various regions, besides the calculation of the standard deviations $(\delta)$ between the generated six groups, guided us to select three optimal wavelengths ( 420,540 and $660 \mathrm{~nm}$ ) to discriminate between these various regions. Next, we selected six spectral images to apply the image processing to (at 450, 500, 550, 600, 650 and 700 nm). We noticed that the optimum image is the superimposed spectral images at 550, 600, 650 and 700 nm, which are capable of discriminating between the various regions. Later, we measured $R_{d}$ with the CCD camera and commercially available monochromatic LED light sources at 415,565 and

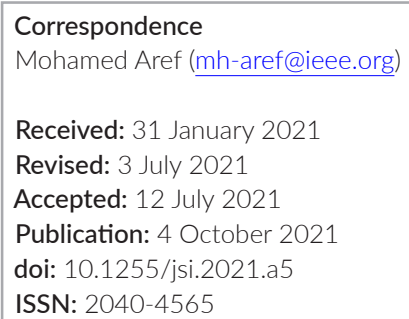

\section{Citation}

M.H. Aref, A.-B.M. Youssef, I.H. Aboughaleb, A.A.R. Sharawi, A.A. Hussein, P. Saccomandi and Y.H. El-Sharkawy, "Prospective study for commercial and low-cost hyperspectral imaging systems to evaluate thermal tissue effect on bovine liver samples", J. Spectral Imaging 10, a5 (2021) https://doi.org/10.1255/jsi.2021.a5

\section{(C) 2021 The Authors}

This licence permits you to use, share, copy and redistribute the paper in any medium or any format provided that a full citation to the original paper in this journal is given, the use is not for commercial purposes and the paper is not changed in any way. 
$660 \mathrm{~nm}$. Compared to the HS camera results, this system was more capable of identifying the ablated and the thermally affected regions of surface RFA than the side-penetration RFA of the investigated ex vivo liver samples. However, we succeeded in developing a low-cost system that provides satisfactory information to highlight the ablated and thermally affected region to improve the outcome of surgical tumour ablation with much shorter time for image capture and processing compared to the HS system.

Keywords: liver cancer, hyperspectral imaging system, RFA, diffuse reflectance, K-means clustering algorithm, monochromatic LEDs

\section{Introduction}

Hepatocellular carcinoma (HCC) is sixth in malignancy rate and third in tumour mortality worldwide. ${ }^{1}$ It is the most widely occurring primary liver cancer, responsible for almost three-quarters of the cases around the world. ${ }^{2}$ $\mathrm{HCC}$ is a critical disease since it is the cause of death of 30,160 in the USA and 781,600 globally. ${ }^{3-5}$ Investigation of the disease needs to be increased in both clinical and pharmaceutical fields, particularly in regions with fewer resources, ${ }^{6}$ such as low-income countries where HCC spread is increasing and early detection methods are limited. ${ }^{7-9}$

There has been a noticeable increase in HCC among patients with liver diseases in Egypt. ${ }^{10}$ Early diagnosis of $\mathrm{HCC}$ is important as few remedial treatment alternatives are available that would be able to provide an improved result. ${ }^{11}$ The ideal therapeutic protocol for patients with HCC is liver transplantation. ${ }^{12-14}$ However, transplantation is restrained by the availability of liver donors and by financial limitations, besides complying with the Milan criteria, ${ }^{15}$ which are a set of criteria for patients with cirrhosis and HCC going for liver transplantation to cure their disease. ${ }^{16,17}$

There has been a significant development recently in the fusion of diagnostic and minimally invasive therapeutic methods with respect to conventional surgeries. ${ }^{18}$ During the resection of cancers in neurosurgery, restorative strategies generally depend on the experience of the neuro-surgeons. ${ }^{19}$ For liver tumour therapy, careful resection is also a regularly utilised technique. ${ }^{20}$ Another therapeutic option for early stage HCC patients with non-cirrhotic livers is hepatic resection. ${ }^{21}$ Minimally intrusive thermal ablation has also proved to be a vital treatment choice when it is available. ${ }^{22}$

Partial hepatectomy provides minimum recovery time and indistinguishable five-year survival rates of $60-70 \%$ compared to transplantation. ${ }^{23}$ However, the number of colorectal cancer $(\mathrm{CLC})$ patients eligible for resection is not much above $25 \%$ because of irregular tumour regions and degraded long-term liver function. ${ }^{24}$ For the remainder of cancers, minimally invasive thermal ablation methods have been demonstrated to be an important treatment choice when available. ${ }^{22}$

Minimally invasive thermal ablation techniques such as radiofrequency ablation (RFA), ${ }^{25}$ laser thermal ablation (LTA), ${ }^{26}$ microwave ablation (MWA), ${ }^{27,28}$ high-intensity focused ultrasound (HIFU) ${ }^{29}$ and bulk thermal ablation $(B T A)^{30,31}$ provide significantly successful results in minimally invasive therapeutic techniques for primary and secondary liver cancers which cannot be removed, ${ }^{25,32,33}$ whereby the main objective of thermal ablation treatment of malignant tumours is to remove the whole tumour by using heat to kill the tumour cells in a minimally invasive way without damaging adjacent essential structures. ${ }^{34}$

Cell homeostasis can keep up with a gentle rise of temperature to roughly $40^{\circ} \mathrm{C}$. Although, the innate acidity and low oxygen tension in malignant cells can give resistance from both radiation and chemotherapy. However, these components render cells more vulnerable to heat. Moreover, the toxicity of a few anti-neoplastic medications and the effectiveness of radiation are improved at higher temperatures (the hyperthermia effect) of $42-45^{\circ} \mathrm{C} .35,36$ On the other hand, even prolonged heat therapy at these temperatures will not destroy all cells in a given volume: cell function and growth of the tumour can still be seen even after moderately long exposure to these temperatures. At the point when temperatures are raised to $46^{\circ} \mathrm{C}$ for $60 \mathrm{~min}$, irreversible cell damage occurs. ${ }^{37}$ The rapid increase of temperature $\left(\geq 60^{\circ} \mathrm{C}\right)$ will cause tumour cell necrosis; this is known as the thermal ablation temperature, ${ }^{30,38,39}$ as explained in Figure A1 in the Appendix.

Giorgio et al. ${ }^{40}$ reported that 71 intrahepatic cholangiocarcinoma (ICC) patients had been treated with MWA (35 patients) and RFA (36 patients); the general survival rates were $88 \%$ at 12 months, $65 \%$ at 36 months, $45 \%$ at 60 months and $34 \%$ at 80 months. The survival rate 
for the patients treated with MWA was higher than RFA-treated patients with ICC nodules of $3-4 \mathrm{~cm}$. However, in the patients with nodules $>4 \mathrm{~cm}$, there was no significant difference. ${ }^{40}$

Recently, numerous scientists have built imaging strategies to ensure appropriate ablation of liver tumours and metastases using non-invasive methods with respect to the conventional hepatectomy method. Of these imaging techniques, diffuse reflectance spectroscopy at wavelengths between $400 \mathrm{~nm}$ and $1050 \mathrm{~nm}$ was used to assess tissue ablation by RFA in eight samples of liver tumour with an average tumour size of $0.8-3.3 \mathrm{~cm}$. The outcome shows high accuracy (97-99\%) in predicting thermal damage with respect to the histology report. ${ }^{22}$ Another study that aimed to predict the temperature changes during hepatic MWA, using dual-energy computed tomography (DECT) imaging, made use of three fluorooptic thermometers for temperature variation measurements through the heating and cooling phases. The results demonstrate that the MWA sensitivity on tissue was inversely linear with DECT image datasets, where regression analysis was performed determining thermal sensitivity for the two phases. The heating phase exhibited the greater influence of temperature compared to the cooling phase. ${ }^{41}$

Hyperspectral imaging (HSI) is a growing imaging method and provides encouraging outcomes in the medical field. For example, a study of LTA with HSI by capturing relative pixel-by-pixel reflectance/absorbance of a broad range spectrum (500-1000 nm) was conducted to investigate in vivo porcine liver to evaluate the spectral response between thermal and normal regions of the organ. The measured absorbance variation was remarkable for methemoglobin at $630 \mathrm{~nm}$, for deoxyhemoglobin at $760 \mathrm{~nm}$ and for water at $960 \mathrm{~nm}$, which confirms the hypothesis that tissue optical behaviour depends on its thermal state. The experimental outcome shows that the methemoglobin absorption in the thermal region was $40 \%$ more than in the non-ablated regions. ${ }^{42,43}$

R.P. Singh-Moon et al. developed a near infrared (NIR) spectroscopic catheter for real-time monitoring of tissue reflection during RFA. The investigation used both a computational model for real-time tissue spectrum classification and ablation size assessment, and an ex vivo porcine cardiac sample for experimental validation. The method could evaluate the RFA lesion size due to the thermal changes in chromophore composition of the investigated tissue in the NIR region. ${ }^{44}$

Additionally, a study of brain tumour identification was successfully achieved within $\sim 1$ min to identify normal and cancer regions by measuring the diffuse reflectance from the light source (tungsten halogen lamp, 150 W, 400-2200 nm) illumination, using two different HSI systems covering the spectral range of $400-1700 \mathrm{~nm}$. Hardware acceleration was used to speed up the processing time during surgery. ${ }^{45}$ The same technique was utilised for non-invasive optical imaging for breast cancer investigations. ${ }^{46,47}$ Additionally, a low-cost system was used to differentiate between normal and malignant breast tissue. ${ }^{48}$

Another study investigated the variations in photoacoustic response signatures of normal and breast tumour tissue. ${ }^{49}$ Additionally, the prospective HSI technique achieves successful results in measuring tissue oxygenation in diagnostic and therapeutic diseases for phlebotomy and non-contact oxygen saturation approaches. ${ }^{50}$ De Landro et al. presented the assessment of LTA outcome in in vivo porcine liver ${ }^{51}$ and gastric mucosa. ${ }^{52}$ Takeshi et al. described the monitoring of hepatectomy associated with developing software to overlay HSI images, ${ }^{53}$ and Boris et al. focused on monitoring blood perfusion for colorectal resections. ${ }^{54}$

Akbari et al..$^{55}$ presented a study to detect non-invasive prostate cancer by measuring the various tissue pixel reflectance, using two different systems. The first system was an in vivo imaging system (Caliper, Hopkinton, MA), which was utilised to capture hyperspectral images for an animal scan at $25 \mu \mathrm{m} /$ pixel resolution, with a wavelength range of 450 950 nm at 2-nm increments. The system used a light source (Xenon, Cermax-type, $300 \mathrm{~W}, 5600^{\circ} \mathrm{K}$ ) that spans the electromagnetic spectrum from $500 \mathrm{~nm}$ to $950 \mathrm{~nm}$. In the second system, a microscopic imaging system was used to scan pathology slides by capturing high-resolution images to permit the identification of the slight spectral differences in tissue, the system has a solidstate tuneable filter with a spectral range of $420 \sim 720 \mathrm{~nm}$. It uses the Sony IC $\times 285$ 2/3" format, 1.4-megapixel $(1392 \times 1040$ pixels), monochrome progressive scan CCD sensor. Each pixel measures $6.45 \mu^{2}$. The analysis of 11 mice demonstrated that the specificity and sensitivity of the HSI system was $96.9 \pm 1.3 \%$ and $92.8 \pm 2.0 \%$, respectively. ${ }^{55}$

Liver tissue interacts with light according to its optical properties (e.g., type/size/density/colour) to provide several wavelength-dependent optical features such as transmission, absorption and diffuse reflectance. ${ }^{56,57}$ The fundamental goal of this investigation is to estimate the diffuse reflectance signal, using a spectral imaging system to recognise and measure the spectral signature of ex vivo liver samples. 
This feasibility study was part of a series of experimental work to highlight the HSI capabilities in RFA observations. Aref et al. used the HSI of ex vivo cow liver to evaluate the variations of the tissue optical properties with different responses to light (transmission, specular reflection, absorption and diffuse reflection) over the whole spectral range and selected the best wavelengths that can distinguish between the different regions (normal/thermally influenced/ablated), see Figure A2 in the Appendix. ${ }^{58-60}$

This study aims to monitor the RFA of the investigated ex vivo liver samples to distinguish between the normal and the ablated regions, as well as the thermally affected regions by measuring the diffuse reflectance $\left(R_{d}\right)$ with two different systems. Initially, a hyperspectral (HS) camera with a polychromatic light source (tungsten halogen lamp) within the spectral range 348-950 nm was employed. Then, the light source was replaced with monochromatic LEDs $(415,565$ and $660 \mathrm{~nm})$ and a commercial CCD camera used instead of the HS camera. An algorithm, comprising image enhancement (normalisation and moving average filter) and image segmentation with $\mathrm{K}$-means clustering, was developed to characterise and evaluate the differences in the reflectance properties of the normal and the ablated regions as well as the thermally affected regions of the ex vivo bovine liver samples. Both the commercial and low-cost systems could be useful during surgery and aid the surgeon in achieving tumour necrosis by monitoring the thermal ablation and avoiding the unnecessary thermal effect. $^{49,61}$

\section{Materials and methods}

In this section, the procedure and methods for the development of trials on RFA of ex vivo bovine liver tissue will be explained, as well as the individual components and their inter-relationships. The imaging system is comprised of seven different elements: the HS camera, the CCD microscopic camera, the thermal camera, the RF generator, the light source (polychromatic or LEDs), the computer and its image processing software, and the liver sample on the white optical board. The first system exploits the HS camera with a polychromatic light source (tungsten halogen lamp, Derungs, 20P SX, 20 Watt) within the spectral range $348-950 \mathrm{~nm}$, as shown in Figure 1a. The second system uses a commercial CCD camera with monochromatic LED illumination (at 415, 565 and $660 \mathrm{~nm}$ ), Figure 1b. A block diagram of the image processing algorithm sequence is presented in Figure 1c.

It takes about 6-10s to capture each image and $<15 \mathrm{~s}$ for calculation using the DADiSP/SE software (DSP Development Corporation, SE, 2017, USA) on a laptop with an Intel Core i7 @1.8 GHz processor with 16GB of RAM.

\section{Sample preparation}

Thermal ablation was performed on five samples from the single bovine liver of a freshly slaughtered animal which was acquired from a local slaughterhouse and transferred in an icebox. The investigated liver portion was cut into five different samples of approximately $5 \times 5 \mathrm{~cm}$ slices with an average weight of $\sim 100 \mathrm{~g}$ for the experimental investigation. The liver samples were packaged in an evacuated wrap using polyethylene (PE) film for preservation purposes. The preserved liver samples were stored at freezing temperature $\left(<-70^{\circ} \mathrm{C}\right)$. The investigation was carried at room temperature $\left(24-26^{\circ} \mathrm{C}\right)$. For the RFA procedure, the liver sample is taken out of the freezer and left in a phosphate-buffered saline (Sigma, P-3813, USA, $\mathrm{pH}$ 7.4) until it reaches ambient temperature $\left(24 \sim 26^{\circ} \mathrm{C}\right)$, monitored with a thermocouple connected to a multimeter (Fluke, 289, USA).

A total of five ablations were performed on the various exvivo liver samples using an RFA system (Premier, 2001e, France), using a $1.2 \mathrm{~mm}$ RF tip with a $2 \mathrm{~cm}$ active blade length. The tip was inserted around $2 \mathrm{~cm}$ into the liver sample under test, and RF power of $50 \mathrm{~W}$ was applied for 2-4 min using the RF generator's impedance-controlled force beating computation to shape ablations ranging in size from around $10 \times 10 \mathrm{~mm}$.

All ablations were imaged within 10 min of thermal ablation and the measurement repeated three times using HSI. Following data acquisition, markers (a transparent ruler placed on a high reflection board) were added to the imaging plane on the different sides of the electrode, and the investigated sample was sliced through the ablated region plane and imaged with both the microscopic CCD camera and the image scanner (HP LaserJet Pro MFP M125, USA); Details are presented in Figure A3 in the Appendix for more detail.

The acquired image of the ablation region in the ex vivo bovine liver tissue was examined at $1200 \mathrm{dpi}$ (scanner resolution) for better comparison with the spectral data. Contour mapping examination of the framework calculation was carried out to identify undesirable thermal damage that was caused by heat conduction from the ablation device. Yellow dashes represent the 


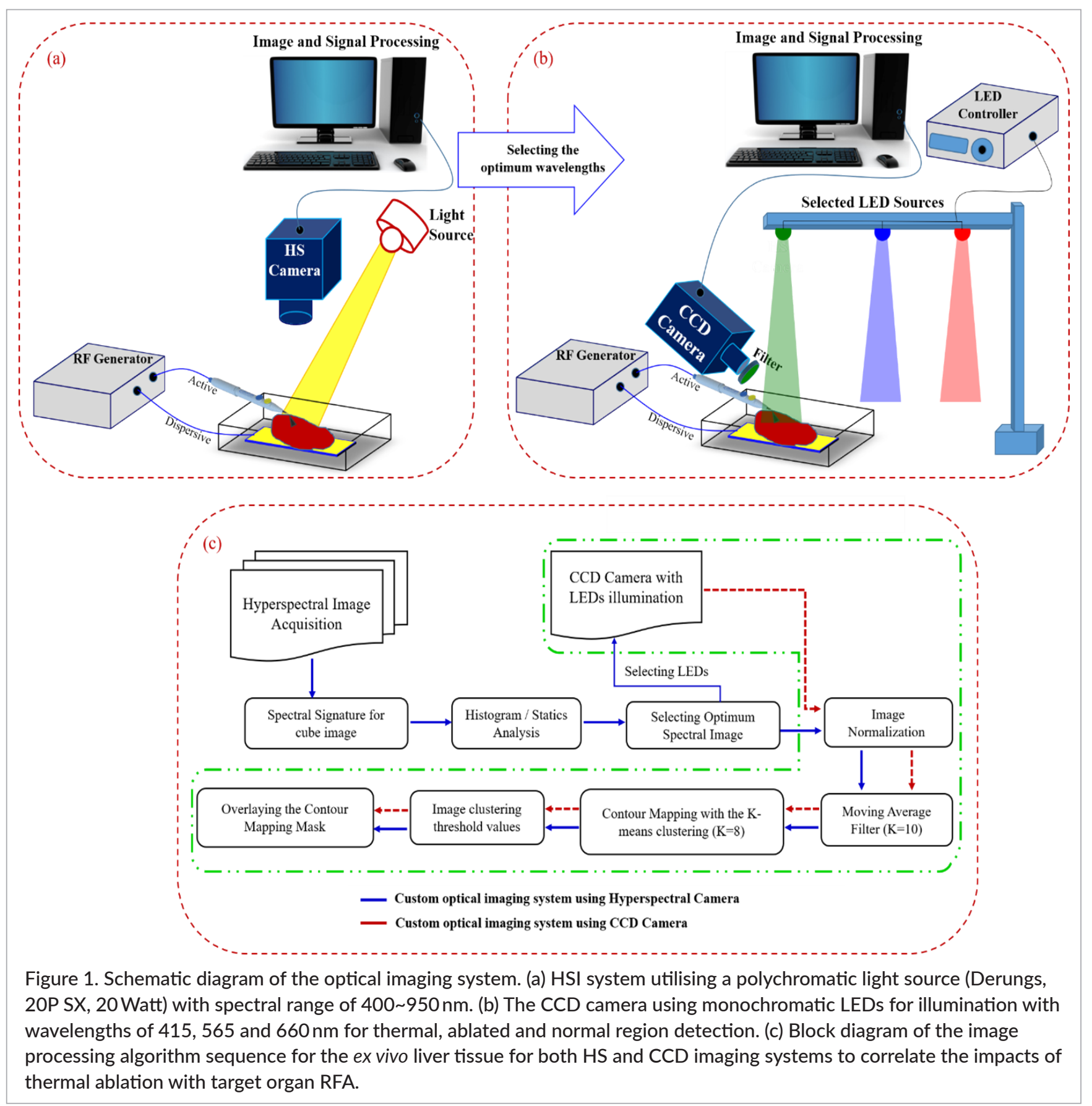

ablated region and red dashes the thermally affected region (Figure 2). After RFA and recording data with both the HS camera and the CCD camera, each sample was preserved in a tissue storage solution (MACS media, $100 \mathrm{~mL}$, Germany) to provide optimised storage of the fresh organ and tissue samples, and packaged in evacuated wrap bags before being sent to the histopathological laboratory.

The gold standard for biopsy investigations is pathology. However, it is intrusive, costly, time-consuming (slicing, sample staining and microscopic analysis) and requires highly trained specialists and pathologists..$^{12,62-64}$ On the other hand, $\mathrm{HSI}$ is an optical imaging method that can quantify the whole investigated sample in a short time (3.6s per HS image), without tissue contact and without the requirement for exogenous contrast agents.

The ablation regions generated from the RFA were evaluated on the ex vivo bovine liver, followed by image processing of the captured spectral data. The output results were then compared with the actual images by an expert pathologist to verify their consistency with the predicted area calculated by the algorithm system. For sample \#1, the thermal area was manually measured after pathology evaluation (pathology is the 

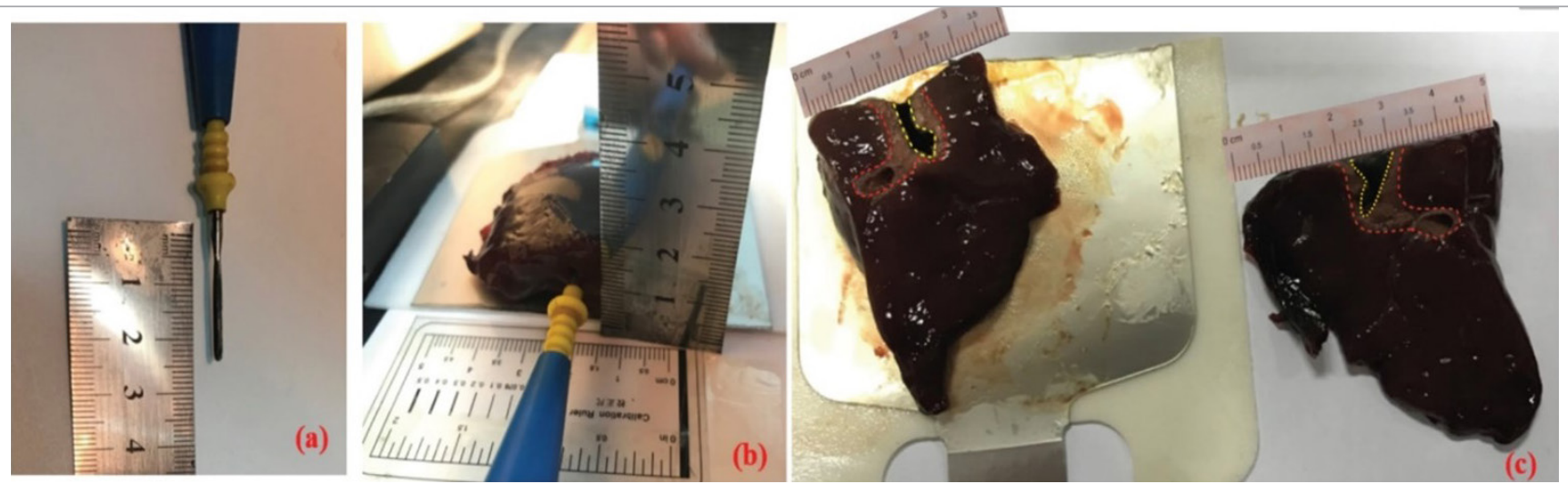

Figure 2. Monitoring and assessment of the thermal depth (z-axis) of a liver sample. (a) Acquired RGB image for the RF active blade length. (b) Cross-section for the RF tip insertion in the liver tissue with position alignment. (c) Scanned image for liver tissue plan view of the sample (coronal plan cross-section) at $1200 \mathrm{dpi}$ resolution to compare it with the predicted thermal area (yellow dashes represent the ablated region and red dashes represent the thermally affected region).

ground truth to validate tissue necrosis and thermal effects), as width (W) of $1.21 \pm 0.14 \mathrm{~cm}$ and length ( $L$ ) of $2.11 \pm 0.09 \mathrm{~cm}$. Whereas, for the ablation region we obtained $W=0.4 \pm 0.07 \mathrm{~cm}$ and $L=1.8 \pm 0.12 \mathrm{~cm}$. Each image pixel corresponds to a specific area on the biological tissue surface of around $\left(0.21 \mathrm{~mm}^{2}\right)$, with a resolution of $\leq 0.4 \mathrm{~mm}$

\section{Optical imaging arrangement for thermal liver ablation observation}

To acquire the HS image information, we utilised a push broom (line-scanning) HS camera in our investigation (Surface Optics, SOC710, USA) with spectral range of $400-1000 \mathrm{~nm}, 5 \mathrm{~nm}$ spectral resolution and $10^{\circ}$ lens (Schneider, 1.9/35 CCTV-LENS, 400-1000 nm). Each
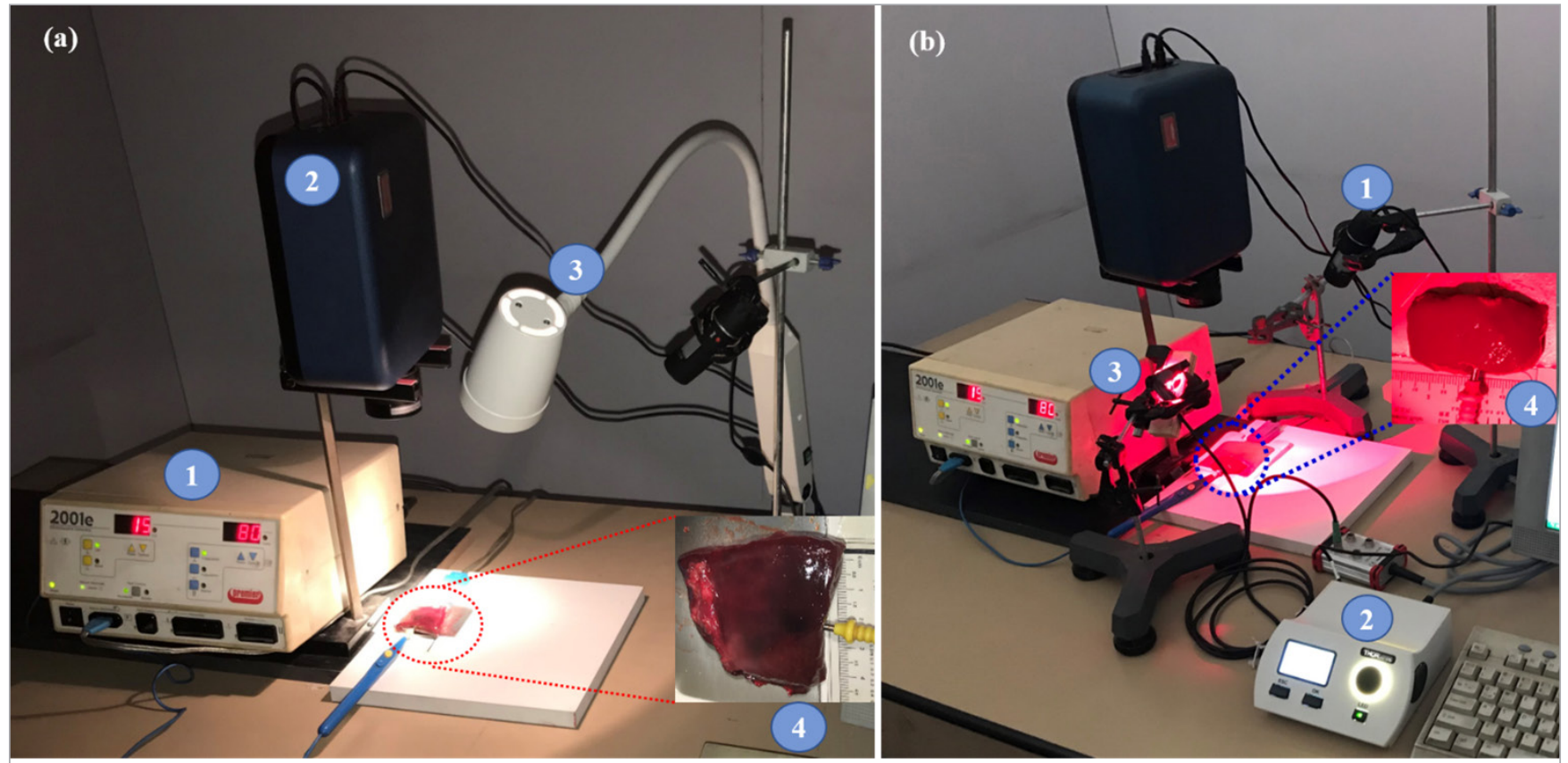

Figure 3. (a) The custom optical imaging system using the HS camera and the polychromatic light source: (1) electrosurgical generator (Premier; 2001e, France); (2) HS camera (Surface Optics, SOC710, USA); (3) the polychromatic light source (Derungs, 20P SX-20 Watt, Germany); (4) the investigated ex vivo liver sample on a white tile with high reflectance (Avian Technologies, FWT-99-300R058, UK). (b) The custom optical imaging system utilising the CCD camera and the monochromatic LEDs: (1) the CCD camera (Microscopic, 500X, China); (2) the monochromatic LEDs driver (Thorlabs, DC4100-HUB, 0-1000 mA, USA); (3) the LEDs at 415, 565 and $660 \mathrm{~nm}$; (4) the investigated ex vivo liver sample on a white tile with high reflectance (Avian Technologies, FWT-99-300R058, UK). 
scanned spectral cube image consisted of 128 frames, each of which represents a specific wavelength.

HS cameras usually require controlled lighting of the captured region to avoid any external interference (e.g., room illumination/daylight effect/time of each exposure and entire experiment/temperature). The illumination system used initially was a polychromatic light (Derungs, 20P SX, 20 Watt, Germany) with a spectral range of $400 \sim 950 \mathrm{~nm}$. This type of light is suitable for HSI purposes because of its broadband, temperature-stable, uniform distribution over the samples and the marker (ruler), and that it can be calibrated from the reference response of the whiteboard; see Figure $3 a$.

Later, the HS camera was replaced with a commercial CCD camera (Microscopic, 500X, China) and the polychromatic light source was replaced with a monochromatic (blue, green, red) LED source, (Thorlabs, DC4100-HUB, 0-1000 mA, USA) at wavelengths of 415, 565 and $660 \mathrm{~nm}$, respectively; see Figure 3b.

The RFA procedure was continuously monitored by a thermal camera (FLIR, ETS 320, USA), which recorded the temperature during the treatment of the investigated ex vivo sample. Additionally, we used a multimeter (Fluke, 289, USA) and a suitable thermocouple for the sample temperature measurements; see Figures A4 and A5 in the Appendix.

\section{Hyperspectral image acquisition}

HS cameras generate a 3-dimensional (3D) data structure, called a hypercube, where the spatial information is found in the first two dimensions, while the third dimension contains the spectral information. ${ }^{65,66}$ In every HS image, each pixel in the scanned image had a different spectral response which varies depending on the selected wavelength and the tissue characteristics. ${ }^{45}$

Three different types/arrangements of hyperspectral images were obtained for each investigated liver sample. Each sample was around $4 \times 5 \mathrm{~cm}$ and was placed in a customised and plexiglass box, with dimensions (width $\times$ length $\times$ depth) of $10 \times 15 \times 5 \mathrm{~cm}$, which maintained the samples at a stable temperature. Line-scan images were recorded for $6 \mathrm{~ms}$ at $4.68 \mathrm{~nm}$ spectral intervals, and each frame comprised 600 -line scans equivalent to $600 \times 502$ pixels per wavelength band (3.6s per HS image). The HS images were comprised of 128 spectral groups in the range $379-1050 \mathrm{~nm}$, integrated with a lens range of $400-1000 \mathrm{~nm}$.

The region of interest (ROI) corresponds to the ablated and the surrounding thermally affected regions as identified by the pathologist and as displayed in Figures $2 \mathrm{c}$ and $4 \mathrm{e}$. The size of each pixel represents $0.22 \times 0.22 \mathrm{~mm}$ of the tissue surface, however, diffuse reflectance achieved with HSI means that the sampling volume is much larger. Consequently, the diffuse reflectance of an individual pixel might represent a spatial resolution for tissue differentiation of $\leq 0.4 \mathrm{~mm}$.

\section{Image analysis and pre-processing}

Image analysis integrates normalisation and de-noising of the raw data image of the reflectance measurements to remove the intensity effect and focus on wavelength differentiation. To reduce processing time, we selected six spectral images to apply the image processing from $450 \mathrm{~nm}$ to $750 \mathrm{~nm}$ with a resolution of $50 \mathrm{~nm}$, rather than the 128 frames from the HS cube. Each raw image is filtered using normalisation and a moving average filter. To remove unnecessary noise, we applied cross-correlation between the filtered images and the reference (polychromatic) light source. We identified the prospective spectral images at wavelengths 550, 600, 650 and $700 \mathrm{~nm}$ at a collage image window, where each wavelength provides different information concerning the optical variation of the tissue. At each wavelength, we could vary the identified region by changing the $\mathrm{K}$-means value. We utilised $\mathrm{K}$-means clustering (KMC) for up to eight clusters to identify the ROI at each wavelength and produce a contour map.

As the temperature of the sensor of the camera rises due to extended usage or longer exposure times, the black level and the noise of the sensor increase significantly. Moreover, dark current effects are corrected after the recording of the data cube using the image processing algorithm we developed. The camera collected and processed the data from the electromagnetic spectrum computing the reflectance spectra generated from the investigated sample. To convert image data from radiance to relative reflectance, we captured a white reference cube with a high diffuse reflectance before the measurements; this also enabled us to correct for spatial differences in the lighting. ${ }^{67}$

One of the main steps in HSI for data normalisation is to acquire a highly reflective image (white cube scan) and a completely dark scan (black cube scan). ${ }^{66}$ The dark scan cube and the white reference cube are considered to be the initial steps for the HS imager calibration and image correction. They work with the custom algorithm to remove any artefacts and noise from the investigated samples, ${ }^{68}$ as shown Equation (1): 


$$
\mathrm{RF}(\phi)=\frac{\operatorname{Im}(\phi)-\operatorname{Id}(\phi)}{\operatorname{IW}(\phi)-\operatorname{Id}(\phi)} \times 100 \%
$$

where $\operatorname{RF}(\phi)$ is the absolute reflectance of the input image, $\operatorname{Im}(\phi)$ is the captured image, $\operatorname{Id}(\phi)$ is the dark image acquired by closing the lens cap and $\operatorname{Iw}(\phi)$ is the acquired image of the white board.

\section{Spectral mapping and acquisition}

The acquired HSI cube of the investigated ex vivo liver tissue samples comprises 128 frames (128 spectral images) over the whole spectral range of $400-1000 \mathrm{~nm}$. From the measured reflectance, we could identify the spectral signature for each region (normal, ablated and thermally affected) across the scanned tissue. The custom processing algorithm incorporates image filtering for the raw image data with normalisation and moving average filter, as shown in Equations (2) and (3).

$$
\begin{gathered}
\tilde{I}_{\text {new }}= \\
\left(\tilde{l}_{\text {preceding }}-m i n_{\text {preceding }}\right) \frac{\max _{\text {new }}-m i n_{\text {new }}}{m a x_{\text {preceding }}-m a x_{\text {preceding }}}+m i n_{\text {new }}
\end{gathered}
$$

where the $n$-dimensional greyscale preceding image $\tilde{I}_{\text {preceding }}:\left\{A \subseteq B^{n}\right\}$ with intensity values in the range given by ( min $_{\text {preceding, }}$, ax $_{\text {preceding }}$ ) is mapped to a new image $\tilde{I}_{\text {new }}:\left\{A \subseteq B^{n}\right\}$ with new intensity values in the range given by $\left(\min _{\text {new }} \max _{\text {new }}\right)$.

We utilised the moving average filter for noise elimination and image improvement, ${ }^{69}$

$$
f(x \times y)=\frac{1}{a t}+\sum_{(r \times c) \in W}^{\infty} s(r \times c)
$$

where $S$ is the noisy image, $f(x \times y)$ is the restored image, and $r$ and $c$ stand for the row and column coordinates, respectively, within a window $W$ of size $q \times t$.

To remove unnecessary noise, we applied crosscorrelation between the filtered images and the reference (polychromatic) light source. We could vary the identified region (normal, ablation, thermally affected) by changing the K-means value. ${ }^{59}$ Generally, contour delineation is an early step for target or organ identification to achieve successful image-guided therapy, usually for some additional processing such as evaluating the characteristics of ROIs or construction of quantitative measurements to observe disease progression. ${ }^{70}$ Then, contour delineation is applied at each wavelength and the
$\mathrm{K}$-means value is changed to reach the optimum value for region identifications.

Since image segmentation is usually applied to trace objects and boundaries, and it is also vital for feature extraction, image measurements and object display in the field of medical images, we used it to delineate the ROls from the images. ${ }^{71,72}$

Finally, we conclude that a longer wavelength penetrated deeper into the investigated tissue and that lower wavelengths were mainly superficial, and that superimposition of all the image segments at 550, 600, 650 and $700 \mathrm{~nm}$ provides the optimum spectral image. So, we combined the four selected wavelengths to provide a complete region identification. Furthermore, the contour image was overlapped on the spectral pictures, where green represents the normal tissue region, red identifies the thermal damage regions and the ablated region is cyan.

We initially scanned the investigated samples with the HS camera to measure $R_{d}$, utilising a polychromatic light source with spectral range of $348-950 \mathrm{~nm}$, to select the optimum wavelength ranges to identify the spectral signature of the various regions. Then we repeated the experiment replacing the polychromatic light source with the blue/green/red LEDs at 415, 565 and $660 \mathrm{~nm}$, and using a commercial CCD camera instead of the HS camera.

The contrast of the scanned images with the CCD camera and LEDs at 415, 565 and $660 \mathrm{~nm}$ was compared by histogram stretching and shown in a bar graph, ${ }^{73-75}$ as explained in Equation (4):

$$
h=\sum_{i=1}^{n} C w_{i} \times f D_{i}
$$

where the area of the histogram is $h$, the class width is $\mathrm{Cw}$ and the frequency density is (fD).

Every pixel point in the investigated sample has different relative reflectance at the various wavelengths that produce the spectrum plot. This is due to the thermal effect, as well as the ablated region having different optical properties (the measured reflectance signature) in the investigated liver tissue compared to the normal liver tissue. The various regions were identified by the pathologist and the spectral signature for each region was measured. We applied custom image processing, initially on the HS data, then on data of the CCD camera to differentiate between the various regions. 


\section{Results}

We imaged the five ex vivo liver samples before and after RFA with the HS camera to identify the spectral signature for each region (normal, ablated and thermally affected) by measuring the $R_{d}$ signature of the selective pixels, as shown in Figure $4 a$. We used the spectral signature of the scanned pixel points from side-penetration RFA over 400-1000 nm as a guide to highlight the differences between the regions (normal, ablated and thermally affected), as shown in Figure 4b. In addition, the spectral signature of the surface RFA of ex vivo liver samples has been identified in a previously published paper. ${ }^{59}$

The diffuse reflectance signatures were computed from the mean of the three different regions of the complete investigated liver tissue samples, which were validated later by the pathologist after thermal ablation and slicing, as shown in Figure $4 c-e$. The investigated samples after RFA were sliced and stored in evacuated wrap bags with tissue storage solution for later evaluation by the pathologist to confirm the ablated and the thermally affected regions, and compare them with the output of the system image processing algorithm.
From the mean values of the measured $R_{d}$ signatures from the three different regions (normal, thermal and ablated regions) of the investigated ex vivo liver tissue samples subject to side-penetration RFA, as shown in Figure $4 \mathrm{~b}$ and compared to the previously measured $R_{d}$ signatures of surface RFA, we were able to build Table 1. We used six groups to guide us in selecting the optimum wavelength for each group, which could identify the three various regions (normal, thermal and ablated regions). Additionally, this was used later to select the suitable wavelength of the monochromatic LED source which will replace the polychromatic light source.

We used the spectral signatures shown in Figure $4 b$ and Table 1 as a guide to select the optimum spectral images which could discriminate between the normal, thermal and ablated regions. Then, we selected six spectral images to apply the image processing from $450 \mathrm{~nm}$ to $750 \mathrm{~nm}$ with resolution of $50 \mathrm{~nm}(450,500,550,600$, 650 and $700 \mathrm{~nm}$ ). Each raw image was filtered utilising normalisation and moving average filter. Furthermore, in order to remove unnecessary noise, we applied crosscorrelation between the filtered images and the captured

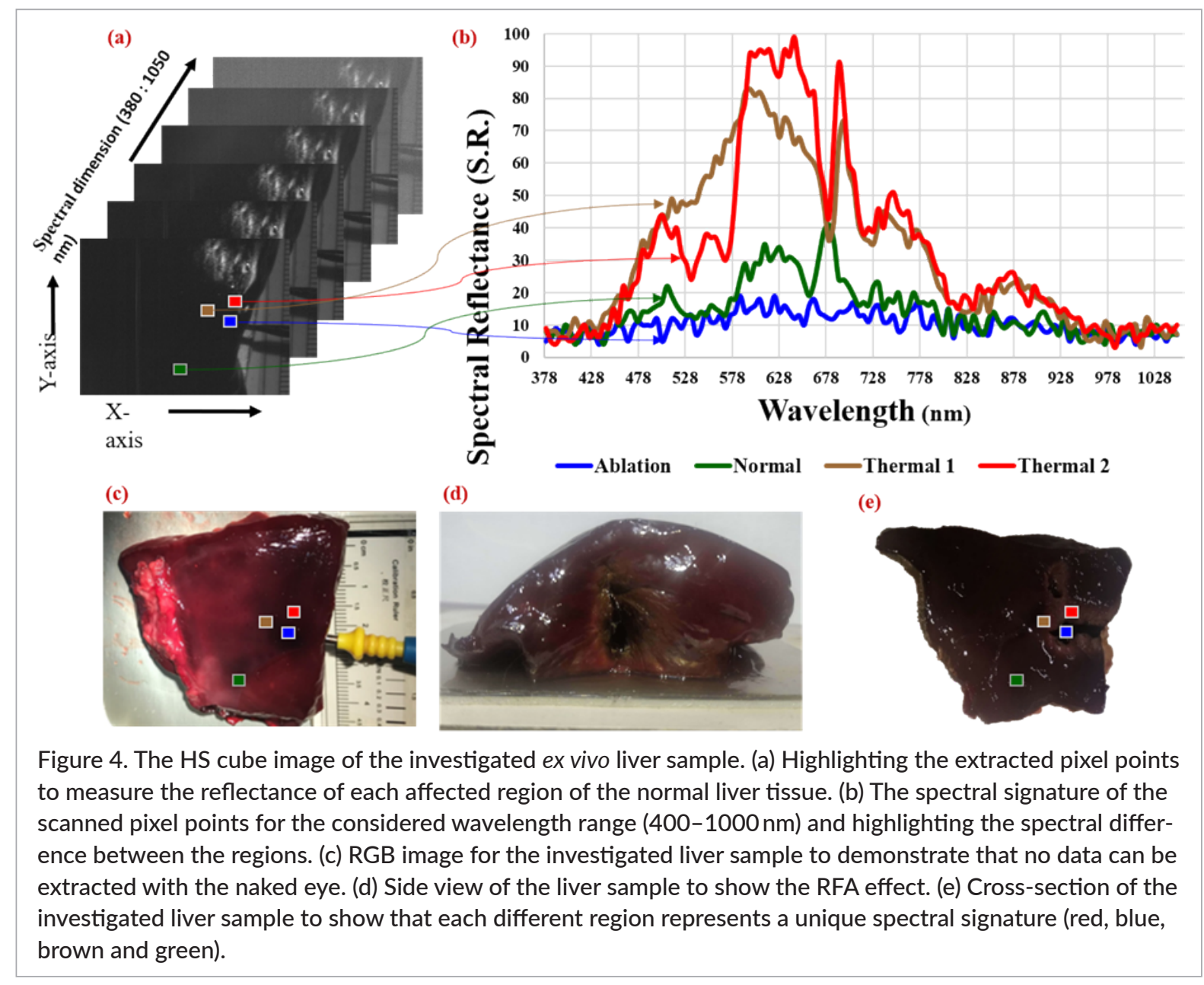



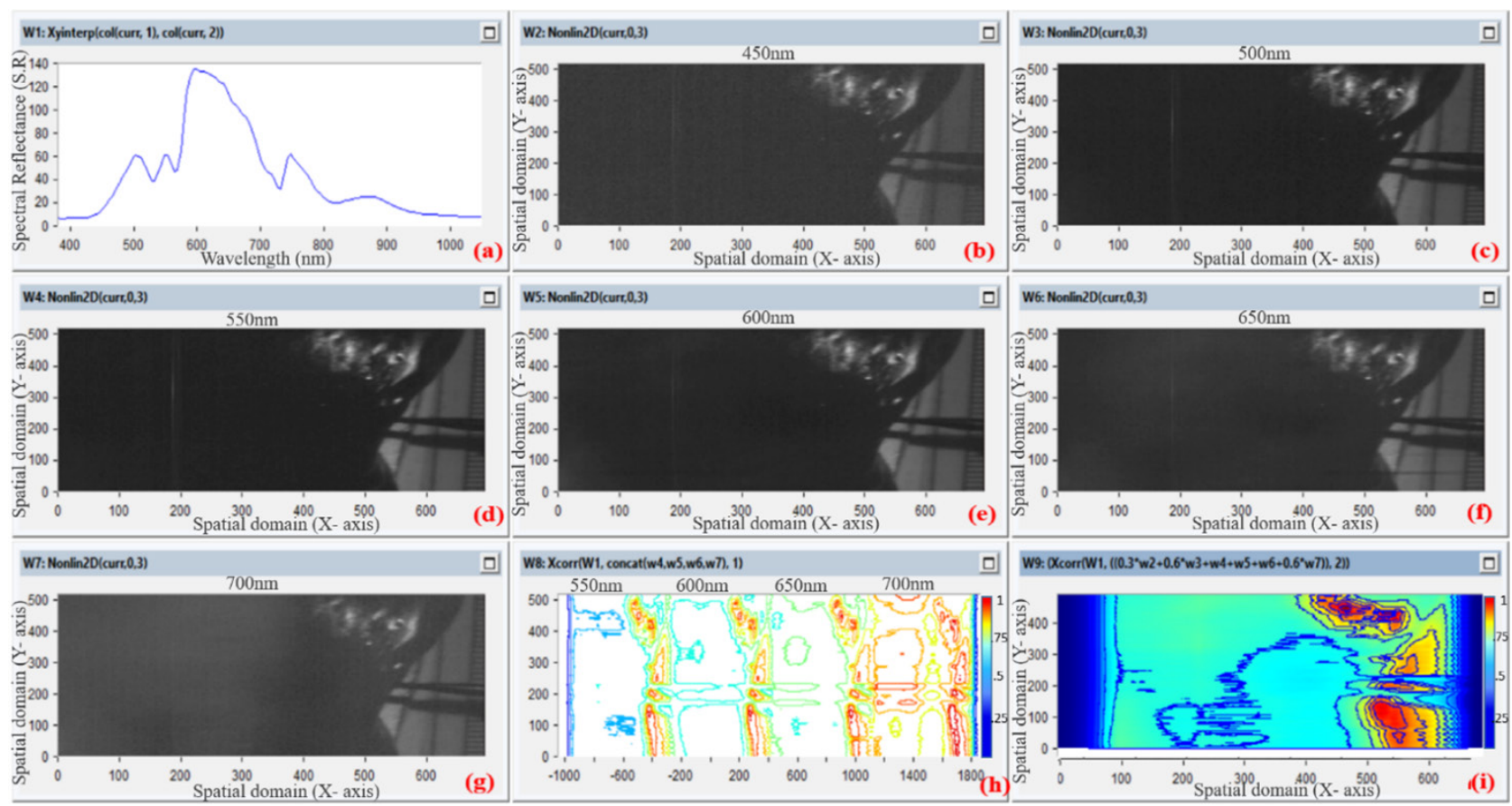

Figure 5. (a) The white reference response of the polychromatic light source, (b) the ex vivo bovine liver sample after ablation for the spectral image at wavelength $450 \mathrm{~nm}$, (c) sample spectral image at wavelength $500 \mathrm{~nm}$, (d) sample spectral image at wavelength $550 \mathrm{~nm}$, (e) sample spectral image at wavelength $600 \mathrm{~nm}$, (f) sample spectral image at wavelength $650 \mathrm{~nm}$, (g) sample spectral image at wavelength $700 \mathrm{~nm}$, (h) the selected prospective spectral images of the side-penetration RFA at 550, 600, 650 and $700 \mathrm{~nm}$ after applying image segmentation with K-means and contour delineation for the different regions (i.e., normal, ablated, thermally affected), (i) the superimposed image of side-penetration RFA of the investigated ex vivo liver sample for the spectral images at 550, 600, 650 and $700 \mathrm{~nm}$, where we could identify the various regions (the normal region in light green (cyan), ablated region in light blue, highly thermally affected (Thermal\#1) in dark orange and the low thermally affected (Thermal\#2) in yellow-light orange.

signature of the polychromatic light source from the whiteboard reference, as shown in Figure 5a. The filtered images for the spectral images (450, 500, 550, 600, 650 and $700 \mathrm{~nm}$ ) are shown in Figure $5 \mathrm{~b}-\mathrm{g}$, respectively.

We identified the prospective spectral images at 550, 600,650 and $700 \mathrm{~nm}$ at a collage image window, where each wavelength provides different information. At each wavelength, we could vary the identified region by changing the K-means value, as shown in Figure $5 \mathrm{~h}$. Finally, the superimposition of all the image segments produces the optimum spectral image, from which we could identify the various regions [normal region in light green (cyan), ablated region in light blue, highly thermally affected (Thermal \#1) in dark orange and the low thermally affected (Thermal \#2) in yellow-light orange], as shown in Figure 5i. "Further details are shown in Figure A6 in the Appendix.

For further clarification, the captured RGB image of the investigated sample with a CCD camera is presented on the left of Figure $6 a$ and its thermal image on the right at the acquired temperature for tissue necrosis $\left(\geq 60^{\circ} \mathrm{C}\right)$.
Next, we applied image segmentation with K-means and contour delineation for the different regions for the selected prospective spectral images at 550, 600, 650 and $700 \mathrm{~nm}$, as shown in Figure 6c. Each wavelength provides different information related to the optical properties of the tissue, since the longer wavelength (700 nm) penetrated deeper into the investigated tissue and the shorter wavelength $(550 \mathrm{~nm})$ was only superficial. Moreover, the regions for the mean value of each wavelength could vary between regions. Finally, we conclude that the superimposed (combined image) of all the spectral images at 550, 600, 650 and $700 \mathrm{~nm}$ is the optimum spectral image, where we could identify the various normal, ablated and thermally affected regions, as shown in Figure 6e.

The same procedure and image processing were applied to the side-penetration RFA samples, as shown in Figure 6b (left) for the RGB image of the investigated sample with a CCD camera and its thermal image (right) at the temperature for tissue necrosis $\left(\geq 60^{\circ} \mathrm{C}\right)$. Then, the applied image segmentation with $\mathrm{K}$-means 

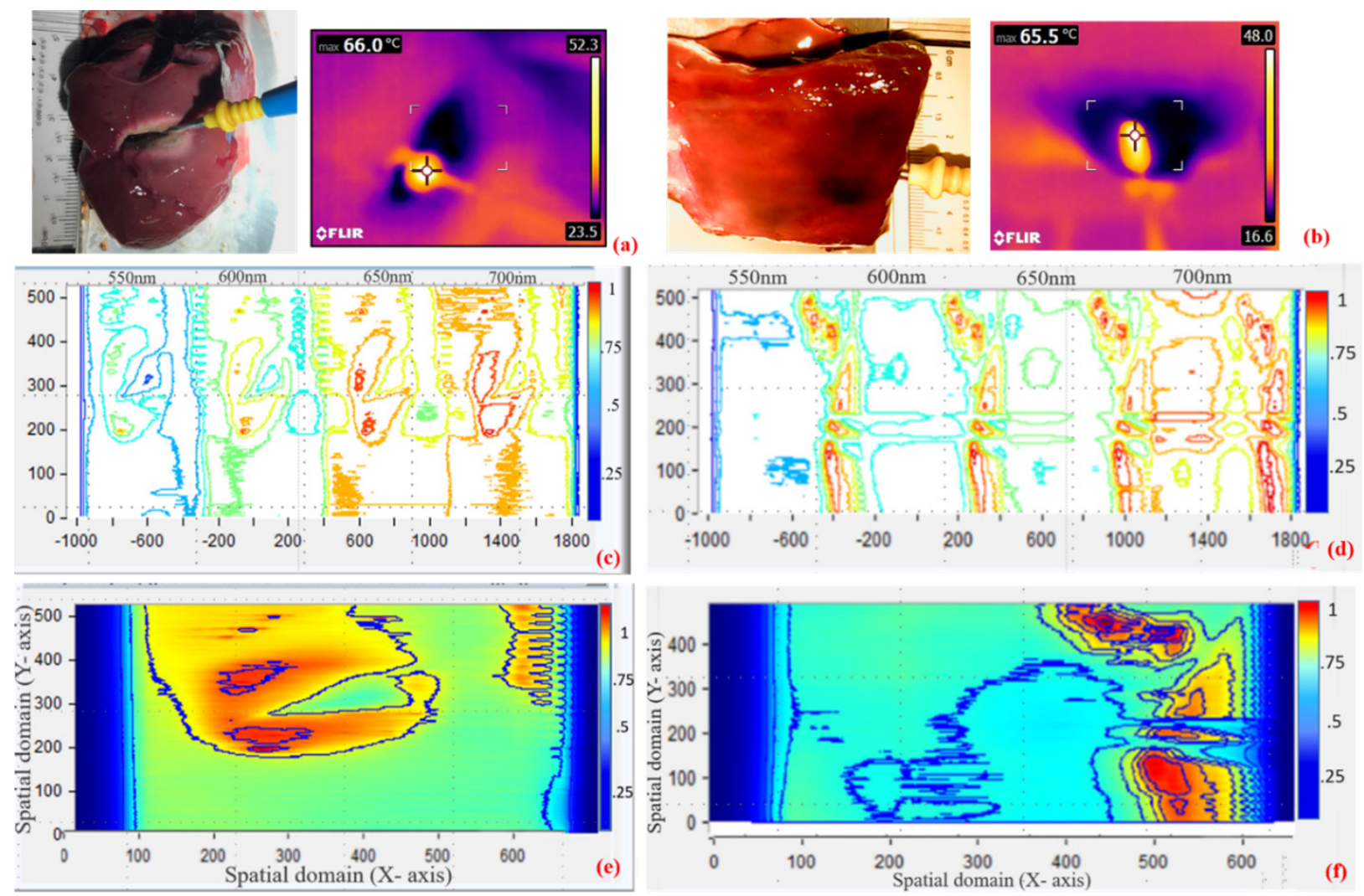

Figure 6. (a) Left: the captured RGB image of the investigated ex vivo liver sample for surface RFA with a commercial CCD camera. Right: the thermal image of the same sample at the temperature required for tissue necrosis $\left(\geq 60^{\circ} \mathrm{C}\right)$. (b) Left: the captured RGB image of the investigated ex vivo liver sample for side-penetration RFA with a commercial CCD camera. Right: the thermal image of the same sample in the at the required temperature for tissue necrosis $\left(\geq 60^{\circ} \mathrm{C}\right)$. (c) The selected prospective spectral images of the surface RFA at 550, 600, 650 and $700 \mathrm{~nm}$ after applying image segmentation with K-means and contour delineation for the different regions (normal, ablated, thermally effected). (d) The selected spectral images of side-penetration RFA at 550, 600, 650 and $700 \mathrm{~nm}$ after applying image segmentation with K-means and contour delineation for the different regions (normal, ablated, thermally effected). (e) The superimposed image of surface RFA for the spectral images at 550, 600, 650 and $700 \mathrm{~nm}$, where we could identify the various regions (normal region in yellow, ablated in cyan, thermally effected in orange and the highly thermally effected by the blue contour region). (f) The superimposed image of side-penetration RFA for the spectral images at 550, 600, 650 and $700 \mathrm{~nm}$, where we could identify the various regions (normal region in yellow, ablated in cyan, thermally effected in orange and the highly thermally effected with the blue contours).

and contour delineation for the different regions for the selected prospective spectral images at 550, 600, 650 and $700 \mathrm{~nm}$, as shown in Figure 6d where each wavelength provides different information related to the optical properties of the tissue, as the longer wavelength $(700 \mathrm{~nm})$ had greater penetration into the investigated tissue and the lower wavelength $(550 \mathrm{~nm})$ was only superficial. Moreover, the regions for every wavelength could be varying concerning the mean value. Finally, we conclude that the superimposed (combined image) of all the spectral images at 550, 600, 650 and $700 \mathrm{~nm}$ is the optimum spectral image, where we could identify the various regions (normal, ablated, thermally affected) regions, as shown in Figure $6 f$.
Figure $A 7$ in the Appendix provides additional clarification for the superimposed captured image of surface RFA and side-penetration RFA to identify the various regions and their colour coding.

Next, we select the suitable wavelengths of the required monochromatic LEDs source with respect to the spectral signature in Figure $4 \mathrm{~b}$ and Table 1 . Then, the light source was replaced with the commercially available LEDs (Thorlabs, USA) at 415, 565 and $660 \mathrm{~nm}$. We used the CCD camera instead of the HS camera to build a low-cost system capable of identifying the same regions by measuring the $R_{d}$. Each sample was illuminated with one of the monochromatic LEDs (415, 565 and $660 \mathrm{~nm}$ ), as displayed in Figures $7 a-c$, respectively. Regarding the 


\begin{tabular}{|c|c|c|c|c|c|c|c|}
\hline & $\stackrel{\infty}{\circledR}$ & $\begin{array}{l}\stackrel{\sim}{n} \\
0 \\
0\end{array}$ & ণ̛ & $\begin{array}{l}\text { Oे } \\
\text { Oे }\end{array}$ & $\stackrel{\circ}{\circ}$ & 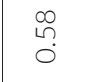 & Нี่ \\
\hline & \& & 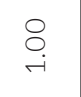 & $\begin{array}{l}\stackrel{+}{ } \\
\stackrel{0}{\circ} \\
\stackrel{0}{0}\end{array}$ & $\stackrel{\circ}{\overrightarrow{0}}$ & $\begin{array}{l}\stackrel{0}{0} \\
\stackrel{0}{0}\end{array}$ & 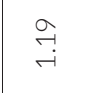 & $\begin{array}{l}\underset{\sigma}{O} \\
\stackrel{-}{-}\end{array}$ \\
\hline & ঃ & $\begin{array}{l}\stackrel{m}{N} \\
\sim\end{array}$ & $\underset{\sim}{\stackrel{\sim}{\sim}}$ & $\begin{array}{l}\stackrel{\circ}{0} \\
0\end{array}$ & 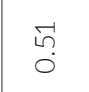 & $\begin{array}{l}\stackrel{\rho}{\wedge} \\
\stackrel{\rho}{n}\end{array}$ & ஸे \\
\hline & $\begin{array}{l}\circ \\
\stackrel{\circ}{\circ}\end{array}$ & $\underset{\stackrel{\overbrace{}}{~}}{\stackrel{f}{7}}$ & $\begin{array}{l}\stackrel{g}{\sigma} \\
\text { c. }\end{array}$ & $\begin{array}{l}\stackrel{n}{0} \\
\stackrel{0}{0}\end{array}$ & î. & in & $\dot{+}$ \\
\hline & ָి & 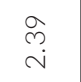 & $\stackrel{\infty}{\stackrel{\infty}{r}}$ & $\begin{array}{l}\stackrel{+}{0} \\
\text { Oे }\end{array}$ & in & $\begin{array}{c}\tilde{\sigma} \\
\stackrel{\leftrightarrow}{\infty}\end{array}$ & ֶָ \\
\hline & $\stackrel{\circ}{\stackrel{\infty}{\wedge}}$ & 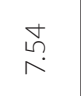 & $\begin{array}{l}\forall \\
\forall \\
b\end{array}$ & $\stackrel{\vec{i}}{i}$ & $\stackrel{ }{\rightarrow}$ & $\begin{array}{l}\text { ¿n } \\
\alpha \\
\alpha\end{array}$ & $\infty$ \\
\hline & 옷 & $\begin{array}{l}\overrightarrow{0} \\
\stackrel{0}{0}\end{array}$ & $\begin{array}{l}\stackrel{\circ}{\circ} \\
\infty\end{array}$ & 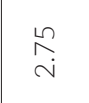 & $\underset{ت}{ت}$ & 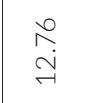 & 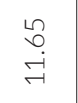 \\
\hline 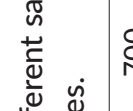 & ঃ & $\begin{array}{l}\stackrel{n}{\alpha} \\
\alpha\end{array}$ & $\begin{array}{l}\vec{f} \\
\stackrel{g}{\rightarrow}\end{array}$ & $\begin{array}{l}\text { in } \\
\text { in }\end{array}$ & $\begin{array}{l}\stackrel{\circ}{\stackrel{2}{*}} \\
\text { ले. }\end{array}$ & $\begin{array}{l}\text { fo } \\
\text { 囟 }\end{array}$ & it \\
\hline 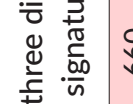 & : & 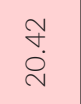 & $\begin{array}{l}\Re \\
\alpha \\
0 \\
\ddots\end{array}$ & $\stackrel{+}{\stackrel{N}{\wedge}}$ & 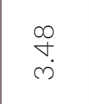 & $\begin{array}{l}\stackrel{n}{N} \\
\underset{\forall}{\forall}\end{array}$ & 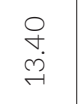 \\
\hline 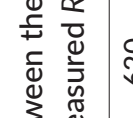 & స్రి & $\begin{array}{l}\vec{\sim} \\
\infty \\
\sim \\
\sim\end{array}$ & 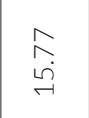 & $\stackrel{\circ}{\stackrel{\circ}{*}}$ & $\stackrel{+}{\stackrel{\sim}{\sim}}$ & $\begin{array}{l}\underset{N}{\infty} \\
\text { oj } \\
\sim\end{array}$ & 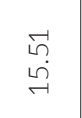 \\
\hline 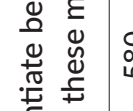 & 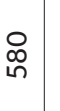 & $\stackrel{\circ}{\circ}$ & $\begin{array}{l}\vec{\Lambda} \\
\stackrel{\vec{\rho}}{\rightarrow}\end{array}$ & 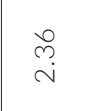 & $\begin{array}{l}\qquad n \\
0 \\
0 \\
b\end{array}$ & $\begin{array}{l}\infty \\
\infty \\
\infty \\
\dot{\sim}\end{array}$ & $\begin{array}{l}\hat{0} \\
\text { aें }\end{array}$ \\
\hline$\stackrel{\mathbb{I}}{E}$ & 옹 & $\begin{array}{l}0 \\
\infty \\
\dot{c}^{2}\end{array}$ & $\begin{array}{l}\hat{o} \\
\text { Gे } \\
\vec{H}\end{array}$ & 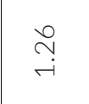 & 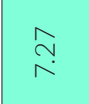 & $\begin{array}{l}\stackrel{n}{\alpha} \\
\stackrel{\omega}{\sim}\end{array}$ & $\stackrel{\infty}{\rightarrow}$ \\
\hline 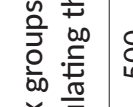 & 品 & 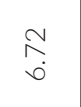 & $\begin{array}{l}\stackrel{n}{n} \\
\stackrel{0}{\circ}\end{array}$ & 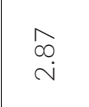 & $\begin{array}{l}\infty \\
\infty \\
\infty \\
\infty\end{array}$ & $\begin{array}{l}\stackrel{n}{n} \\
\stackrel{0}{0}\end{array}$ & $\bar{N}$ \\
\hline a & 웅 & $\stackrel{\substack{\infty \\
i}}{i}$ & $\underset{\stackrel{\gamma}{\curvearrowright}}{\stackrel{f}{r}}$ & 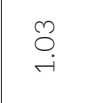 & $\stackrel{\circ}{\stackrel{\leftrightarrow}{i}}$ & $\stackrel{\substack{\infty \\
\sim}}{\stackrel{n}{a}}$ & \\
\hline 임 & ঙ্ণি & 웅 & 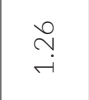 & $\stackrel{\text { O̊. }}{\circ}$ & $\stackrel{\overbrace{}}{\stackrel{f}{ت}}$ & $\stackrel{m}{\stackrel{\sim}{0}}$ & $\stackrel{\sim}{\sim}$ \\
\hline$\frac{1}{8}$ & 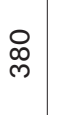 & $\begin{array}{l}\infty \\
0 \\
0\end{array}$ & $\begin{array}{l}\infty \\
\stackrel{\sim}{0}\end{array}$ & $\begin{array}{l}\stackrel{L}{\circ} \\
\stackrel{0}{0}\end{array}$ & $\stackrel{\circ}{\stackrel{\leftrightarrow}{0}}$ & $\stackrel{m}{\stackrel{m}{0}}$ & a \\
\hline 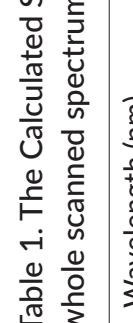 & 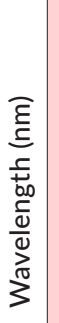 & 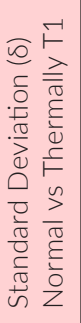 & 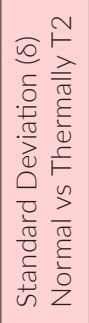 & 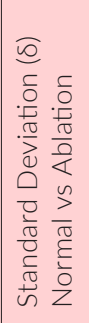 & 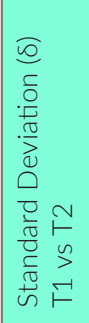 & 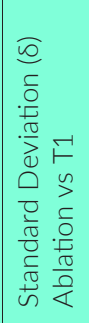 & 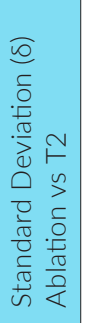 \\
\hline
\end{tabular}

histogram analysis for each image, the samples illuminated with the blue LED $(415 \mathrm{~nm})$, the green monochromatic LED $(565 \mathrm{~nm})$ and the red LED $(660 \mathrm{~nm})$ sources, are shown in Figure $7 d-f$, respectively. The histogram is related to the image contrast. So that, a more stretched histogram indicates a larger number of pixels and ones which are well distributed over the whole image, as a result of an image with good contrast. Finally, we noticed that each wavelength gives different information, from low penetration with a shorter wavelength $(415 \mathrm{~nm})$ to high penetration with longer wavelength $(660 \mathrm{~nm})$.

The histogram analysis which illustrates the image contrast for each sample illuminated with specific monochromatic LEDs and the histogram analysis of the combination of the three wavelengths together is displayed in Figure A8 in the Appendix.

Figure 8 illustrates the image processing of the investigated ex vivo liver samples captured with the commercial CCD camera and illuminated with the LEDs. The captured RGB image of the investigated ex vivo liver samples is displayed in Figure 8a, the captured images of the investigated ex vivo liver sample illuminated with the blue LED $(415 \mathrm{~nm})$, green LED $(565 \mathrm{~nm})$ and red LED $(660 \mathrm{~nm})$ are displayed in Figure $8 \mathrm{~b}-\mathrm{d}$, respectively. Then, we removed the noise and enhanced the captured images with the image enhancement process (normalisation and moving average filter), as shown in Figure $8 \mathrm{e}-\mathrm{g}$, respectively. Furthermore, applying the contour delineation for the different regions (i.e., normal, ablated, thermally affected) after applying image segmentation with the $\mathrm{K}$-means method and the regions vary regarding the mean value. Finally, we overlaid the contour delineation of the captured RGB image of the investigated ex vivo liver sample, as presented in Figure 8i.

To evaluate the customised low-cost system performance, we utilised one of the previous samples which had been monitored with the HS camera and the polychromatic light source. The investigated ex vivo liver sample after surface RFA was captured with the CCD camera and illuminated with the red LED $(660 \mathrm{~nm})$, as shown in Figure 9a. We applied the same image processing, which incorporates noise removal, image enhancement with normalisation and moving average filter, as displayed in Figure 9b. Then, image segmentation with the KMC method highlighted the ablated and the thermally affected regions by changing the mean value, as shown in Figure 9c and d, respectively. Furthermore, we overlaid the image of the contour delineation for the ablated and the thermally affected regions over the captured image of the investigated ex vivo liver sample, as displayed in 


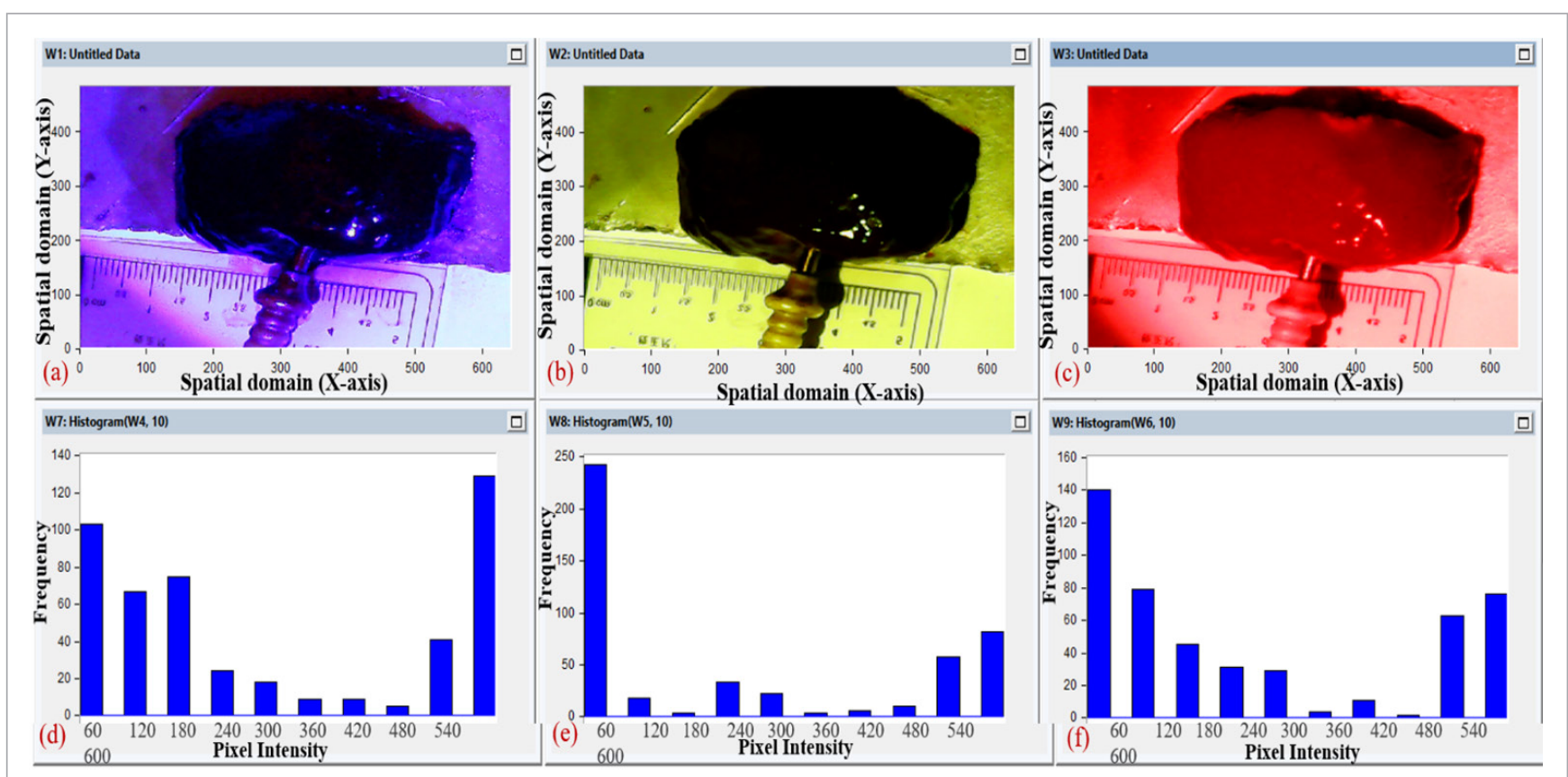

Figure 7. The histogram analysis of the investigated ex vivo liver samples captured with the commercial CCD camera and illuminated with the monochromatic LEDs at 415, 565 and $660 \mathrm{~nm}$. (a) The captured image of the ex vivo liver sample with the monochromatic blue LED at $415 \mathrm{~nm}$. (b) The captured image of the ex vivo liver sample measured with the monochromatic green LED at $565 \mathrm{~nm}$. (c) The captured image of the ex vivo liver sample with the monochromatic red LED at $660 \mathrm{~nm}$. (d) The histogram stretching analysis to measure the image contrast of the captured image with the blue LED at $415 \mathrm{~nm}$. (e) The histogram stretching analysis to measure the image contrast of the captured image with the green LED at $565 \mathrm{~nm}$. (f) The histogram stretching analysis to measure the image contrast of the captured image with the red LED at $660 \mathrm{~nm}$.

Figure $9 e$ and $f$, respectively. We repeat the same steps of the captured image for side-penetration RFA of the investigated ex vivo liver sample, as shown in Figure 10.

\section{Discussion}

Non-invasive thermal ablation, such as RFA, MWA and laser ablation, is a leading therapeutic approach for non-resected liver tumours, where thermal observation with a well-chosen image-guided system is vital to achieving succesful removal of tumours with the least possible thermal damage to other liver tissues. ${ }^{76-79}$

The work presented in this study aims to establish a commercial, low-cost optical imaging system to evaluate the observation of RFA on ex vivo liver samples to distinguish between the normal, ablated and thermally affected regions by measuring the $R_{d}$ of these regions. RFA trials were conducted on five different ex vivo normal bovine samples and monitored initially by an HS camera with spectral range of 400-1000 nm and with a polychromatic light source with range of $348-950 \mathrm{~nm}$.
The measured $R_{d}$ of each pixel was generated from the thermal and ablated regions of the investigated liver tissue surface compared to normal tissue (the liver sample region which had been affected by neither ablation nor thermal), as shown in Figure 4a. The degree and level of the thermal effect on the tissue could be related to the spectral wavelength and used to distinguish the selective regions. The $R_{d}$ signatures were computed from the mean of the three different regions on the investigated liver tissue sample. The regions were identified later by the pathologist after thermal ablation and slicing, as shown in Figure 4c-e. These derived signals are shown in the spectra highlighting the distinctive spectral signatures of the normal, ablated and thermal regions, as displayed in Figure 4b.

Table 1 demonstrates the calculation of the standard deviation ( $\delta$ ) between the six generated groups. The $\delta$ at $660 \mathrm{~nm}$ was capable of distinguishing between the normal and the thermal effect (T1) region group, the normal and the thermal effect (T2) region group and the normal and the ablation region group. However, the $\delta$ at $540 \mathrm{~nm}$ was the best for differentiating between the T1 and $\mathrm{T} 2$ region group and the $\mathrm{T} 1$ and the ablation region 

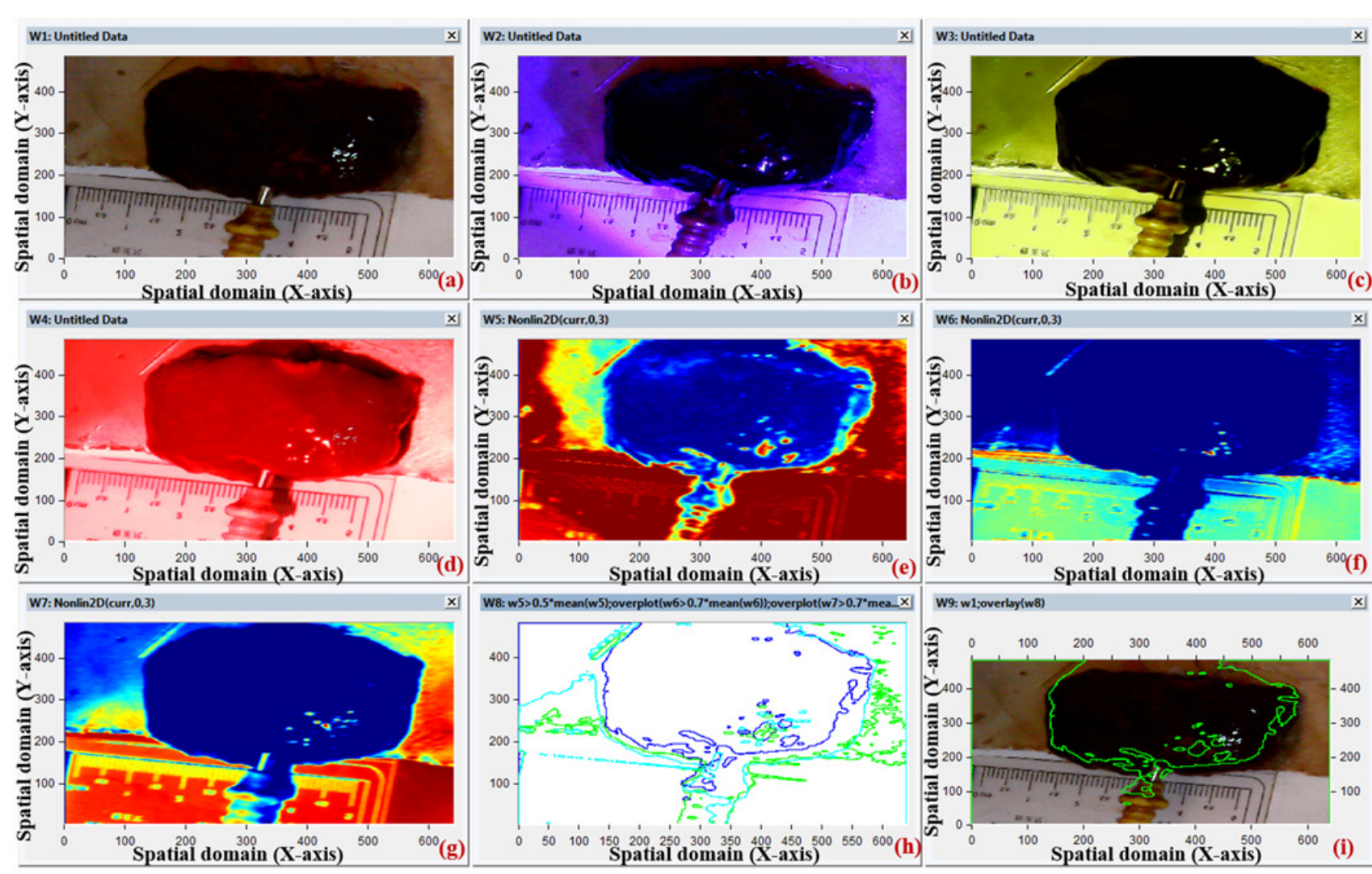

Figure 8. The image processing of the investigated ex vivo liver samples captured with the commercial CCD camera and illuminated with the monochromatic LEDs at 415,565 and $660 \mathrm{~nm}$. (a) The captured RGB image of the investigated ex vivo liver sample with the commercial CCD camera. (b) The captured image of the investigated ex vivo liver sample illuminated with the blue LED $(415 \mathrm{~nm})$. (c) The captured image of the investigated ex vivo liver sample illuminated with the green LED $(565 \mathrm{~nm})$. (d) The captured image of the investigated ex vivo liver sample illuminated with the red LED (660 nm). (e) Using the image enhancement process (normalisation and moving average filter) for the captured image with the blue LED $(415 \mathrm{~nm})$. ( $f)$ Using image enhancement (normalisation and moving average filter) for the captured image with the green LED $(565 \mathrm{~nm})$. (g) Using image enhancement (normalisation and moving average filter) for the captured image with the red LED $(660 \mathrm{~nm})$. (h) The contour delineation for the different regions (normal, ablated, thermally affected) after applying image segmentation with K-means method. (i) The contour delineation for the different regions (normal, ablated, thermally affected) overlaid on the captured RGB image of the investigated ex vivo liver sample with the commercial CCD camera.

group. Finally, the $\delta$ at $420 \mathrm{~nm}$ was ideal for discriminating between the $\mathrm{T} 2$ and the ablation region groups.

We used the spectral signatures of the side-penetration RFA ex vivo liver samples from Figure $4 b$, in addition to the previous measured spectral signature of the surface RFA ex vivo liver samples ${ }^{59}$ and the calculation of the $\delta$, as shown in Table 1, as a guide to selecting the optimum spectral images which can discriminate between the three regions (normal, ablated and thermal affected regions). The results of this step were used also for selecting the suitable wavelength of the monochromatic LED source which will replace the polychromatic light source.

Then, we selected six spectral images to apply the image processing from $450 \mathrm{~nm}$ to $750 \mathrm{~nm}$ with resolution of $50 \mathrm{~nm}$, rather than the 128 frames from the HS cube to reduce processing time. Working on the entire HS cube (128 frames) will take at least 40 min. In contrast, when selecting the six spectral images, the processing takes only $324 \mathrm{~s}=5.4 \mathrm{~min}$. Each raw image had been filtered utilising normalisation and the moving average filter. Furthermore, to remove unnecessary noise, we applied cross-correlation between the filtered images and the captured signature of the polychromatic light source from the whiteboard reference, as shown in Figure 5a. The filtered images for the spectral images (450, 500, 550, 600, 650 and $700 \mathrm{~nm})$ are displayed in Figures $5 b-$ g, respectively.

We identified the prospective spectral images at the mentioned wavelengths, excluding the spectral images at $450 \mathrm{~nm}$ and $500 \mathrm{~nm}$, as they did not provide enough 


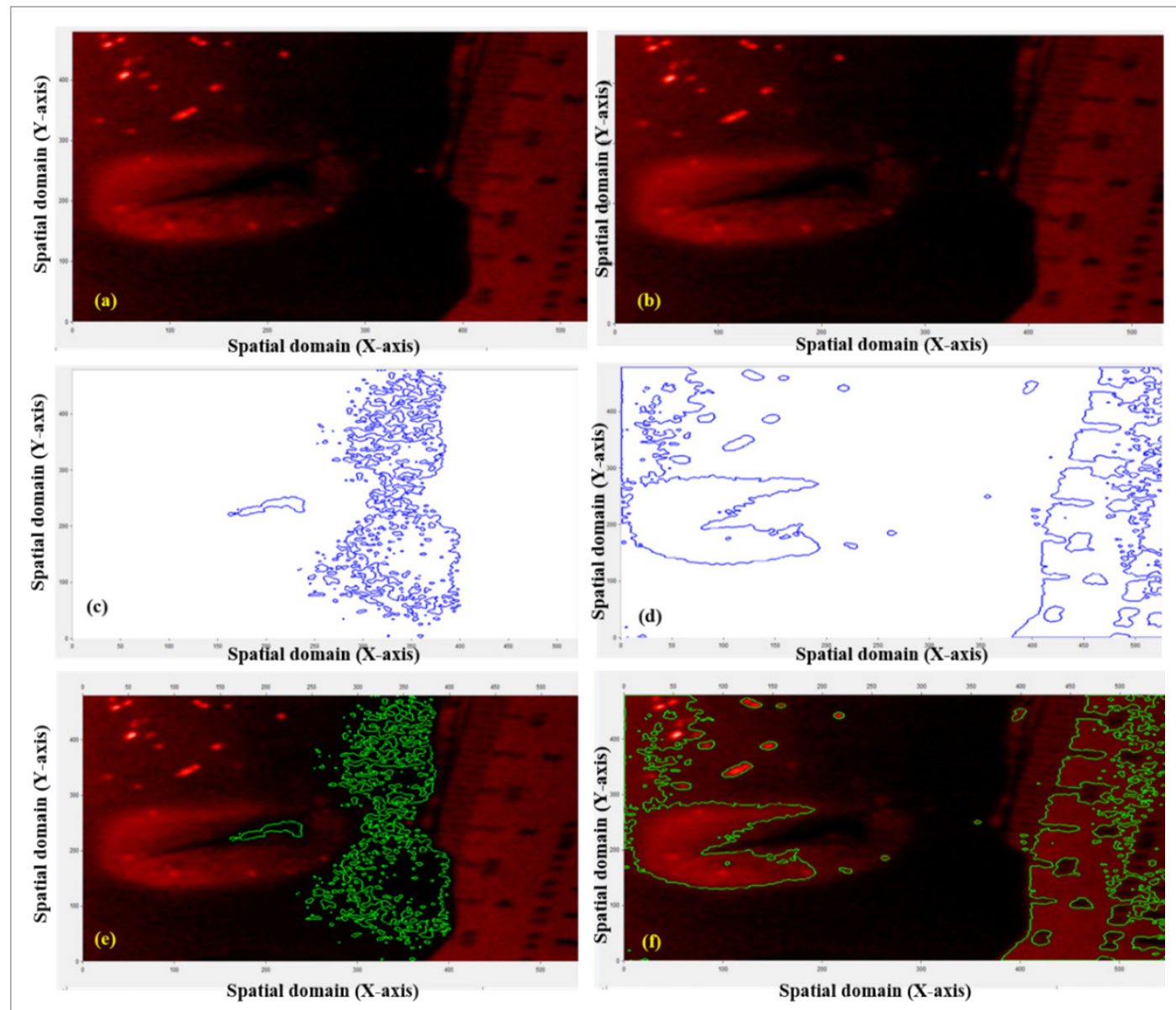

Figure 9. (a) The captured image of the surface RFA for the investigated ex vivo liver sample measured with the commercial CCD camera and illuminated with the light source red LED $(660 \mathrm{~nm})$.

(b) The captured image after image processing incorporating noise removal, image enhancement with normalisation and moving average filter. (c) The contour delineation for image segmentation of the captured image with the KMC method highlighting the ablated region. (d) The contour delineation for image segmentation of the captured image with the K-means method highlighting the thermally affected region. (e) The overlaid image for contour delineation of the sample ablated region over the captured image of the investigated ex vivo liver sample with the commercial CCD camera and the light source red LED $(660 \mathrm{~nm})$. (f) The overlaid image for contour delineation of the sample thermally affected region over the captured image of the investigated ex vivo liver sample with the commercial CCD camera and the light source red LED $(660 \mathrm{~nm})$.

information to distinguish between the different regions. Each wavelength provides different information and at each wavelength, we could vary the identified region by changing the K-means value, as displayed in Figure $5 \mathrm{~h}$.

Consistent with the principles of biomedical optics, ${ }^{56,57}$ we observed that the longer wavelength pentrated further into the investigated tissue than the shorter wavelength. Then, we noticed that the spectral image from superimposition of all segments was the optimum, where we could identify the various regions: normal in light green (cyan), ablated in light blue, highly thermally affected (Thermal \#1) in dark orange and low thermally affected (Thermal \#2) in yellow-light orange, as shown in Figure $5 i$.
Figure 6 provides an additional explanation for the investigated ex vivo liver tissue surface RFA, which has been retrieved from the worksheet in Figure A6 in the Appendix, and the side-penetration RFA retrieved from the worksheet in Figure 5. Applied image segmentation with $\mathrm{K}$-means could delineate the different regions from the selected prospective spectral images at 550, 600, 650 and $700 \mathrm{~nm}$, as shown in Figure 6c and d. However, each wavelength provides different information related to the optical properties of the tissue, as the longer wavelength $(700 \mathrm{~nm})$ has greater penetration and the lower wavelength $(550 \mathrm{~nm})$ is more superficial on the investigated tissue. Thus, the superimposed (combined image) 

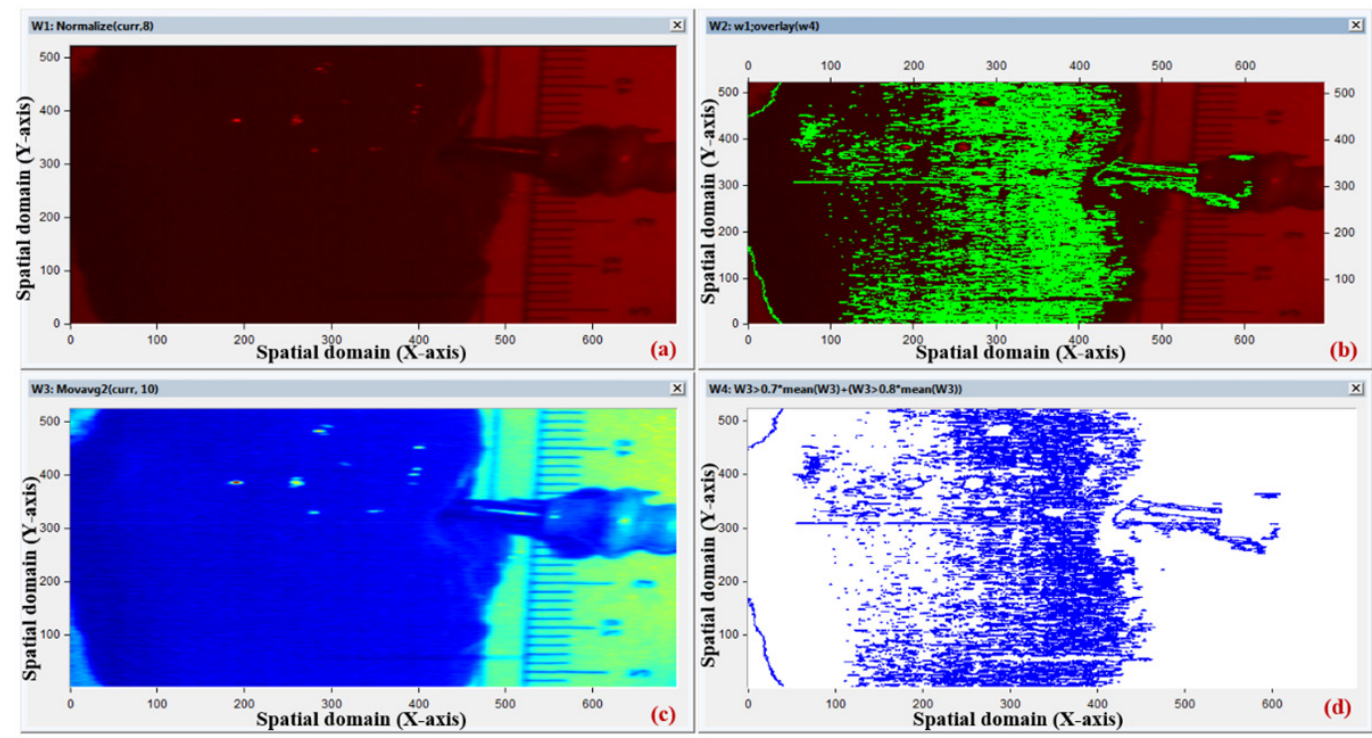

Figure 10. (a) The captured image of the side-penetration RFA for the investigated ex vivo liver sample using the commercial CCD camera and illuminated with the red LED $(660 \mathrm{~nm})$. (b) The overlaid image for contour delineation of the thermally affected region over the captured image of the investigated ex vivo liver sample with the commercial CCD camera and the red LED $(660 \mathrm{~nm})$. (c) The captured image after image processing (noise removing, image enhancement with the normalisation and moving average filter). (d) The contour delineation for image segmentation of the captured image with the KMC method higlighting the thermally affected region.

of all the spectral images at wavelengths $(550,600,650$ and $700 \mathrm{~nm}$ ) represents the optimum spectral image, as we could identify the various regions (normal, ablated, thermally affected) regions, as shown in Figure be and f. Additionally, Figure A7 in the Appendix demonstrates additional clarification for the superimposed image of both the surface and side-penetration RFA.

Next, we choose the suitable wavelengths for the monochromatic LEDs source based on the spectral signature in Figure $4 \mathrm{~b}$ and Table 1. The light source was replaced with monochromatic LEDs at 415, 565 and $660 \mathrm{~nm}$ (commercially available) and a commercial CCD camera was used instead of the HS camera to build a low-cost system capable of identifying the same regions by measuring the $R_{d}$. Each sample was illuminated with one of the three monochromatic LEDs, as displayed in Figures $7 a-c$, respectively. Regarding the histogram analysis for each image, the samples illuminated with the blue LED $(415 \mathrm{~nm})$ were highly absorbed, had low reflection and low contrast. The green monochromatic LED wavelength $(565 \mathrm{~nm})$ was lower in absorption than the blue wavelength, leading to better reflection. However, the samples which illuminated with the red LED $(660 \mathrm{~nm})$ source, transmitted and had respectable contrast, as shown in Figure $7 d-f$, respectively.
We used histogram analysis to compare the pixel intensity with the various wavelengths (frequencies). The histogram is related to the image contrast. So that, the more stretched histogram means a large number of pixels, well distributed over the whole image, as a result of a good contrast image. Later, we noticed that each wavelength gives different information, from low penetration with the short wavelength $(415 \mathrm{~nm})$, to higher penetration at the long wavelength $(660 \mathrm{~nm})$. These results validate our previous results utilising the HS camera (Figure 6) and the biological tissue interaction with light, as shown in Figure A2 in the Appendix.

Figure A8 in the Appendix demonstrates the histogram analysis of the captured images for the investigated ex vivo liver samples with the commercial CCD camera and illuminated with the monochromatic LEDs at 415, 565 and $660 \mathrm{~nm}$, where the captured image with the blue LED illumination at $415 \mathrm{~nm}$ is represented by the blue bars, green LED illumination at $565 \mathrm{~nm}$ by the green bars and red LED illumination at $660 \mathrm{~nm}$ by the cyan bars. Finally, the superimposed image of the three monochromatic wavelengths (blue + green + red) is represented by the red bars.

We applied the image processing to the captured images of the investigated ex vivo liver samples in Figures $8 b-d$. Then, we removed the noise and enhanced the captured 
images with the image enhancement process (normalisation and moving average filter), as shown in Figure $8 \mathrm{e}-\mathrm{g}$. Subsequently, contour delineation was applied on normal, ablated and thermally affected regions resulting from the K-means segmentation of the image. Finally, we overlaid the contour delineation of the captured RGB image of the investigated ex vivo liver sample, as presented in Figure 8i.

To evaluate the performance of the customised low-cost system, we used one of the previous samples which had been monitored with the HS camera and the polychromatic light source. The investigated ex vivo liver sample after surface RFA was imaged with the CCD camera and illuminated with the monochromatic light source red LED $(660 \mathrm{~nm})$, since it had the largest penetration depth into the tissue (Figure 9a). Then the same image processing, which incorporates noise removal, image enhancement with normalisation and moving average filter, was applied (Figure 9b). Then, image segmentation with the K-means method highlighted the ablated and the thermally affected regions by changing the mean value, as shown in Figure $9 c$ and d, respectively. Furthermore, we overlaid the image of the contour delineation for the ablated and the thermally affected region over the captured image of the investigated ex vivo liver sample, as shown in Figure $9 e$ and $f$, respectively. We repeated the same steps on the image from side-penetration RFA of the investigated ex vivo liver sample, as shown in Figure 10.

Finally, we could successfully identify the ablated and the thermally effected regions for the investigated ex vivo liver subjected to surface RFA with the system using the CCD camera and red LED (660 nm), as shown in Figures 9e and $\mathrm{f}$, respectively, and from the results of the initial system using the HS camera, as presented previously in Figure 6c and e, and Figure A7a and b in the Appendix. However, imaging the side-penetration RFA with the system using the CCD camera and the red LED $(660 \mathrm{~nm})$, as shown in Figure 10b, provides minimal information regarding the ablation and the thermally affected regions due to the variation of the microscopic lens resolution compared to the results of the system from the HS camera (Figure 5, Figure $6 \mathrm{~d}$ and $\mathrm{f}$ and Figure $\mathrm{A} 7 \mathrm{c}$ and $\mathrm{d}$ in the Appendix).

\section{Conclusion}

In brief, the proposed approach reveals the HS camera capabilities to provide useful information to assist surgeons by early delineation of the thermal effects to avoid overheating by ablation or incomplete treatment of the tumour site cell necrosis due to the lack of the accuracy and the reliability for the exploited method, or due to lack of experience. HSI is expensive compared to a commercial CCD camera; additionally, it cannot work in real-time, due to the time needed for image capture and processing. To overcome this, we initially used a HS camera to measure the $R_{d}$ of the investigated ex vivo liver samples with a polychromatic light source covering the spectral range of $348-950 \mathrm{~nm}$. These spectral signatures and the calculation of the $\delta$ between the generated six groups provided the guidance to select three optimal wavelengths $(420,540$ and $660 \mathrm{~nm}$ ) to discriminate between the various regions (normal, ablated and thermally affected). Next, we selected six spectral images (450, 500, 550, 600, 650 and $700 \mathrm{~nm}$ ) to apply the image processing, and we found that the optimum for discriminating between the various regions is the superimposed spectral images at wavelengths 550, 600, 650 and $700 \mathrm{~nm}$. Later, the HS camera was replaced with a commercial CCD camera to measure the $R_{d}$ with the commercially available monochromatic LEDs source light, at 415, 565 and $660 \mathrm{~nm}$. The system was better at identifying the ablated and the thermally affected regions of surface RFA than the side-penetration RFA of the investigated ex vivo liver samples compared to the HS camera. However, we succeeded in reducing the capture and image processing time and providing satisfactory information to highlight the ablated and thermally affected region with a low-cost system. Our examination was restricted to ex vivo liver tissue and we intend to do additional investigations on actual liver tumours for ex vivo samples in our future work, then moving further to endoscopic investigations, as illustrated in Figure A9 in the Appendix. In the future, we plan to evaluate the system in real-time with various cases to consider all the limitations (such as heat sink effect of large vessels next to the ablation zone) and its advantages (low-cost system, non-contact).

\section{Declarations}

The authors declare and state that the work was affirmed by the Ethics Committee of Ain Shams Faculty of Medicine, Cairo, Egypt.

The authors also declare and state that they have all the research data and all the materials are available on request.

The authors further declare and state that they have no competing interests. 


\section{References}

1. J. Ferlay, H.-R. Shin, F. Bray, D. Forman, C. Mathers and D.M. Parkin, "Estimates of worldwide burden of cancer in 2008: GLOBOCAN 2008", Int. J. Cancer 127, 2893-2917 (2010). https://doi.org/10.1002/ ijc. 25516

2. Y.-F. Liaw, "Antiviral therapy of chronic hepatitis B: Opportunities and challenges in Asia", J. Hepatol.

51, 403-410 (2009). https://doi.org/10.1016/j. jhep.2009.04.003

3. P.H. Viale, "The American Cancer Society's facts \& figures: 2020 edition", J. Adv. Pract. Oncol. 11, 135-136 (2020). https://doi.org/10.6004/jadpro.2020.11.2.1

4. H.D. AL-Mozan, H.M. Mousa and B.J. Al-Badry, "Prevalence of cancer disease in Thi_Qar Provence", J. Phys. Conf. Ser. 1294(6), 062039 (2019). https:// doi.org/10.1088/1742-6596/1294/6/062039

5. M. Marmot, "Health equity, cancer, and social determinants of health", Lancet Glob. Health 6, S29 (2018). https://doi.org/10.1016/S2214-109X(18)30098-6

6. P. Ferenci, M. Fried, D. Labrecque, J. Bruix, M. Sherman, M. Omata, J. Heathcote, T. Piratsivuth, M. Kew, J.A. Otegbayo, S.S. Zheng, S. Sarin, S.S. Hamid, S.B. Modawi, W. Fleig, S. Fedail, A. Thomson, A. Khan, P. Malfertheiner, G. Lau, F.J. Carillo, J. Krabshuis and A. Le Mair, "Hepatocellular carcinoma (HCC): A global perspective", J. Clin. Gastroenterol.

44, 239-245 (2010). https://doi.org/10.1097/ MCG.0b013e3181d46ef2

7. M.C. Kew, "Hepatocellular carcinoma in developing countries: Prevention, diagnosis and treatment", World J. Hepatol. 4, 99-104 (2012). https://doi. org/10.4254/wjh.v4.i3.99

8. M. Puoti, D. Manno, P. Nasta and G. Carosi, "Hepatitis B virus and HIV coinfection in low-income countries: unmet needs", Clin. Infect. Dis. 46(3), 367-369 (2008). https://doi.org/10.1086/525532

9. J. Rickard, G. Beilman, J. Forrester, R. Sawyer, A. Stephen, T.G. Weiser and J. Valenzuela, "Surgical infections in low-and middle-income countries: A global assessment of the burden and management needs", Surg. Infect. 21(6), 478-494 (2020). https:// doi.org/10.1089/sur.2019.142

10. S. Abd-Elsalam, N. Elwan, H. Soliman, D. Ziada, W. Elkhalawany, M. Salama, N. Hawash, M. Arafa, R. Badawi and W.M. Shehata, "Epidemiology of liver cancer in Nile delta over a decade: A single-center study", South Asian J. Cancer 7(1), 24-26 (2018). https://doi.org/10.4103/sajc.sajc_82_17
11. T. Hennedige and S.K. Venkatesh, "Imaging of hepatocellular carcinoma: diagnosis, staging and treatment monitoring", Cancer Imaging 12(3), 530-547 (2012). https://doi.org/10.1102/14707330.2012 .0044

12. T. Longerich, K. Breuhahn and P. Schirmacher, "Molecular pathology of liver tumors", in Molecular Surgical Pathology, Ed by L. Cheng and J. Eble. Springer (2013). https://doi.org/10.1007/978-14614-4900-3_3

13. J. Ferlay, I. Soerjomataram, R. Dikshit, S. Eser, C. Mathers, M. Rebelo, D.M. Parkin, D. Forman and F. Bray, "Cancer incidence and mortality worldwide: sources, methods and major patterns in GLOBOCAN 2012", Int. J. Cancer 136(5), E359-E386 (2015). https://doi.org/10.1002/ijc.29210

14. W.M. Rashed, M.A.M. Kandeil, M.O. Mahmoud and S. Ezzat, "Hepatocellular Carcinoma (HCC) in Egypt: A comprehensive overview", J. Egypt. Natl. Canc. Inst. 32, 5 (2020). https://doi.org/10.1186/s43046-0200016-x

15. M.J. Englesbe, S.P. Patel, K. He, R.J. Lynch, D.E. Schaubel, C. Harbaugh, S.A. Holcombe, S.C. Wang, D.L. Segev and C.J. Sonnenday, "Sarcopenia and mortality after liver transplantation", J. Am. Coll. Surg. 211, 271-278 (2010). https://doi.org/10.1016/j. jamcollsurg.2010.03.039

16. W. Liu, Y. Zheng, W. He, R. Zou, J. Qiu, J. Shen, Z. Yang, Y. Zhang, C. Wang, Y. Wang, D. Zuo, B. Li and Y. Yuan, "Microwave vs radiofrequency ablation for hepatocellular carcinoma within the Milan criteria: a propensity score analysis", Aliment Pharm. Ther. 48(6), 671-681 (2018). https://doi.org/10.1111/ apt.14929

17. F. Gunsar, "Liver transplantation for hepatocellular carcinoma beyond the Milan criteria", Exp. Clin. Transplant. Off. J. Middle East Soc. Organ Transplant. 15, 59-64 (2017).

18. H. Liao, "Integrated diagnostic and therapeutic techniques: toward an intelligent medical system", Comput. Med. Imaging Graph. 38(5), 421-422 (2014). https://doi.org/10.1016/j.compmedimag.2014.05.008

19. N. Sanai, M.-Y. Polley, M.W. McDermott, A.T. Parsa and M.S. Berger, "An extent of resection threshold for newly diagnosed glioblastomas", J. Neurosurg. 115(1), 3-8 (2011). https://doi.org/10.3171/2011.2. JNS10998

20. B.K.P. Goh, J.-Y. Teo, C.-Y. Chan, S.-Y. Lee, P.-C. Cheow, P.K.H. Chow, L.L.P.J. Ooi and A.Y.F. Chung, 
"Evolution of laparoscopic liver resection at Singapore General Hospital: a nine-year experience of 195 consecutive resections", Singapore Med. J.

58(12), 708-713 (2017). https://doi.org/10.11622/ smedj.2016188

21. A. Forner, M. Gilabert, J. Bruix and J.L. Raoul, "Treatment of intermediate-stage hepatocellular carcinoma", Nat. Rev. Clin. Oncol. 11, 525-535 (2014). https://doi.org/10.1038/nrclinonc.2014.122

22. E. Tanis, J.W. Spliethoff, D.J. Evers, G.C. Langhout, P. Snaebjornsson, W. Prevoo, B.H.W. Hendriks and T.J.M. Ruers, "Real-time in vivo assessment of radiofrequency ablation of human colorectal liver metastases using diffuse reflectance spectroscopy", Eur. J. Surg. Oncol. 42(2), 251-259 (2020). https://doi. org/10.1016/j.ejso.2015.12.005

23. J. Bruix, M. Reig and M. Sherman, "Evidence-based diagnosis, staging, and treatment of patients with hepatocellular carcinoma", Gastroenterology 150(4), 835-853 (2016). https://doi.org/10.1053/j.gastro.2015.12.041

24. E.J.A. Morris, D. Forman, J.D. Thomas, P. Quirke, E.F. Taylor, L. Fairley, B. Cottier and G. Poston, "Surgical management and outcomes of colorectal cancer liver metastases", Br. J. Surg. 97(7), 11101118 (2010). https://doi.org/10.1002/bjs.7032

25. T. Livraghi, H. Mäkisalo and P.-D. Line, "Treatment options in hepatocellular carcinoma today", Scand. J. Surg. 100(1), 22-29 (2011). https://doi. org/10.1177/145749691110000105

26. C.E. Tatsui, R.J. Stafford, J. Li, J.N. Sellin, B. Amini, G. Rao, D. Suki, A.J. Ghia, P. Brown, S. Lee, C.E. Cowles, J.S. Weinberg and L.D. Rhines, "Utilization of laser interstitial thermotherapy guided by realtime thermal MRI as an alternative to separation surgery in the management of spinal metastasis", J. Neurosurg. 23(4), 400-411 (2015). https://doi. org/10.3171/2015.2.SPINE141185

27. C.L. Brace, "Microwave tissue ablation: Biophysics, technology, and applications", Crit. Rev. Biomed. Eng. 38, 65-78 (2010). https://doi.org/10.1615/ CritRevBiomedEng.v38.i1.60

28. B.O. Imene, B.A. Farid and B.O. Khaoula, "CT-guided microwave liver tumors ablation and automatic adjustment of frequency", Averroes Eur. Med. J. 2(1) (2018). http://www.averroes-emj.com/articles/ ctguided-microwave-liver-tumors-ablation-and-automatic-adjustment-of-frequency-24.html

29. J. Macdonell, N. Patel, S. Rubino, G. Ghoshal, G. Fischer, E.C. Burdette, R. Hwang and J.G. Pilitsis,
"Magnetic resonance-guided interstitial highintensity focused ultrasound for brain tumor ablation", J. Neurosurg. 44(2), 1-6 (2018). https://doi. org/10.3171/2017.11.FOCUS17613

30. H. Zhi-yu, L. Ping, Y. Xiao-ling, C. Zhi-gang, L. Fang-yi and Y. Jie, "A clinical study of thermal monitoring techniques of ultrasound-guided microwave ablation for hepatocellular carcinoma in high-risk locations", Sci. Rep. 7, 41246 (2017). https://doi. org/10.1038/srep41246

31. H. Takahashi, M. Akyuz, E. Aksoy, K. Karabulut and E. Berber, "Local recurrence after laparoscopic radiofrequency ablation of malignant liver tumors: Results of a contemporary series", J. Surg. Oncol. 115(7), 830-834 (2017). https://doi.org/10.1002/ jso.24599

32. T.R. Fosnight, F.M. Hooi, R.D. Keil, A.P. Ross, S. Subramanian, T.G. Akinyi, J.K. Killin, P.G. Barthe, S.M. Rudich, S.A. Ahmad, M.B. Rao and T.D. Mast, "Echo decorrelation imaging of rabbit liver and VX2 tumor during in vivo ultrasound ablation, Ultrasound Med. Biol. 43(1), 176-186 (2017). https://doi. org/10.1016/j.ultrasmedbio.2016.08.025

33. T.J. Vogl, A. Dommermuth, B. Heinle, N.-E.A. Nour-Eldin, T. Lehnert, K. Eichler, S. Zangos, W.O. Bechstein and N.N.N. Naguib, "Colorectal cancer liver metastases: long-term survival and progression-free survival after thermal ablation using magnetic resonance-guided laser-induced interstitial thermotherapy in 594 patients analysis of prognostic factors", Invest. Radiol. 49(1), 48-56 (2014). https:// doi.org/10.1097/RLI.0b013e3182a6094e

34. S.N. Goldberg, G.S. Gazelle and P.R. Mueller, "Thermal ablation therapy for focal malignancy. A unified approach to underlying principles, techniques, and diagnostic imaging guidance", Am. J. Roentgenol. 174(2), 323-331 (2000). https://doi. org/10.2214/ajr.174.2.1740323

35. M.H. Seegenschmiedt, L.W. Brady and R. Sauer, "Interstitial thermoradiotherapy: review on technical and clinical aspects", Am. J. Clin. Oncol. 13(4), 352363 (1990). https://doi.org/10.1097/00000421199008000-00016

36. J. Overgaard, "Hyperthermia as an adjuvant to radiotherapy", Strahlenther Onkol. 163, 453-457 (1987).

37. R.M. Pohlman, T. Varghese, J. Jiang, T.J. Ziemlewicz, M.L. Alexander, K.L. Wergin, J.L. Hinshaw, M.G. Lubner, S.A. Wells and F.T. Lee Jr, "Comparison of displacement tracking algorithms for in vivo electrode displacement elastography", UItrasound 
Med. Biol. 45(1), 218-232 (2019). https://doi. org/10.1016/j.ultrasmedbio.2018.09.001

38. A.M. James, Thermal and Energetic Studies of Cellular Biological Systems. Butterworth-Heinemann (2016).

39. R. Jafari, H. Almqvist, H. Axelsson, M. Ignatushchenko, T. Lundbäck, P. Nordlund and D.M. Molina, "The cellular thermal shift assay for evaluating drug target interactions in cells", Nat. Protoc. 9, 2100-2122 (2014). https://doi.org/10.1038/ nprot.2014.138

40. A. Giorgio, P. Gatti, L. Montesarchio, B. Santoro, A.D. Olio, N. Crucinio, C. Coppola, F. Scarano, F. De Biase, E. Ciracì, S. Semeraro and V. Giorgio, "Intrahepatic cholangiocarcinoma and thermal ablation: Iong-term results of an Italian retrospective multicenter study", J. Clin. Transl. Hepatol. 7(4), 287-292 (2019). https://doi.org/10.14218/ JCTH.2019.00036

41. J. Paul, T.J. Vogl and A. Chacko, "Dual energy computed tomography thermometry during hepatic microwave ablation in an ex-vivo porcine model", Eur. J. Med. Phys. 31(7), 683-691 (2015). https://doi. org/10.1016/j.ejmp.2015.05.014

42. M. De Landro, M. Barberio, E. Felli, V. Agnus, M. Pizzicannella, M. Diana and P. Saccomandi, "Hyperspectral image-based analysis of thermal damage in living liver undergoing laser ablation", Proc. SPIE 11362, 113620G (2020). https://doi. org/10.1117/12.2555465

43. M. De Landro, P. Saccomandi, M. Barberio, E. Schena and M. Diana, "Hyperspectral imaging for thermal effect monitoring in in vivo liver during laser ablation", 2019 41st Annu. Int. Conf. IEEE Eng. Med. Biol. Soc. pp. 1851-1854 (2019). https://doi. org/10.1109/EMBC.2019.8856487

44. R.P. Singh-Moon, X. Yao, V. Iyer, C. Marboe, W. Whang, C.P. Hendon, "Real-time optical spectroscopic monitoring of nonirrigated lesion progression within atrial and ventricular tissues", J. Biophotonics 12, 1-14 (2019). https://doi.org/10.1002/ jbio. 201800144

45. H. Fabelo, S. Ortega, R.L. Id, D.M. Id, G.M. Callic, E. Ju, D. Bulters, H.B. Id, A. Szolna, J.F. Piñeiro, C. Sosa, A.J.O. Shanahan, S. Bisshopp, D. Ravi, B.R. Kiran, A. Vega, B. Abelardo, G. Yang, B. Stanciulescu and R. Sarmiento, "An intraoperative visualization system using hyperspectral imaging to aid in brain tumor delineation", Sensors 18(2), 430 (2018). https://doi. org/10.3390/s18020430
46. I.H. Aboughaleb, M.H. Aref and Y.H. El-Sharkawy, "Hyperspectral imaging for diagnosis and detection of ex-vivo breast cancer", Photodiagnosis Photodyn. Ther. 31, 101922 (2020). https://doi.org/10.1016/j. pdpdt.2020.101922

47. M. Aref, I.H. Aboughaleb, A.-B. Youssef and Y. El-Sharkawy, "Novel approach exploiting the hyperspectral imaging system for breast cancer therapy and diagnosis", Arch. Breast Cancer 7(4), 189-201 (2020). https://doi.org/10.32768/abc.202074189201

48. M.H. Aref, I.H. Aboughaleb and Y.H. El-Sharkawy, "Custom optical imaging system for ex-vivo breast cancer detection based on spectral signature", Surg. Oncol. 35, 547-555 (2020). https://doi. org/10.1016/j.suronc.2020.10.019

49. Y.H. El-Sharkawy, "Optical properties of non-malignant and malignant breast tissue determined by surface displacement of laser-induced photoacoustic generation", Int. J. Opt. Photon. Eng. 1(1), 1-8 (2016). https://doi.org/10.35840/2631-5092/4502

50. M.H.F. Aref, A.A.R. Sharawi and Y.H. El-Sharkawy, "Delineation of the arm blood vessels utilizing hyperspectral imaging to assist with phlebotomy for exploiting the cutaneous tissue oxygen concentration", Photodiag. Photodyn. Ther. 33, 102190 (2021). https://doi.org/10.1016/j.pdpdt.2021.102190

51. M. De Landro, I.E. García-Molina, M. Barberio, E. Felli, V. Agnus, M. Pizzicannella, M. Diana, E. Zappa and P. Saccomandi, "Hyperspectral imagery for assessing laser-induced thermal state change in liver", Sensors 21(2), 643 (2021). https://doi. org/10.3390/s21020643

52. M. De Landro, M. Barberio, E. Felli, V. Agnus, M. Pizzicannella, M. Dlana, P. Saccomandi, "Hyperspectral imaging system for monitoring laser-induced thermal damage in gastric mucosa", 2020 IEEE International Symposium on Medical Measurements and Applications (MeMeA), pp. 1-6 (2020). https://doi.org/10.1109/ MeMeA49120.2020.9137230

53. T. Urade, E. Felli, M. Barberio, M. Al-Taher, E. Felli, L. Goffin, V. Agnus, G.M. Ettorre, J. Marescaux, D. Mutter and M. Diana, "Hyperspectral enhanced reality (HYPER) for anatomical liver resection", Surg. Endosc. 35, 1844-1850 (2021). https://doi. org/10.1007/s00464-020-07586-5

54. B. Jansen-Winkeln, I. Germann, H. Köhler, M. Mehdorn, M. Maktabi, R. Sucher, M. Barberio, C. Chalopin, M. Diana, Y. Moulla and I. Gockel, 
"Comparison of hyperspectral imaging and fluorescence angiography for the determination of the transection margin in colorectal resections-a comparative study", Int. J. Colorectal Dis. 36, 283291 (2021). https://doi.org/10.1007/s00384-02003755-z

55. H. Akbari, L. Halig, D.M. Schuster, B. Fei, A. Osunkoya, V. Master, P. Nieh and G. Chen, "Hyperspectral imaging and quantitative analysis for prostate cancer detection", J. Biomed. Opt. 17(7), 076005 (2012). https://doi.org/10.1117/1. JBO.17.7.076005

56. V. Tuchin, "Tissue optics and photonics: light-tissue interaction II", J. Biomed. Photonics Eng. 2(3), 030201 (2016). https://doi.org/10.18287/JBPE16.02.030201

57. V.V Tuchin, "Tissue optics and photonics: biological tissue structures", J. Biomed. Photonics Eng. 1(1), 3-21 (2015). https://doi.org/10.18287/JBPE-2015-11-3

58. M.H. Aref, I.H. Aboughaleb, A.-B.M. Youssef and Y.H. El-Sharkawy, "Hyperspectral image-based analysis of thermal damage for ex-vivo bovine liver utilizing radiofrequency ablation", Surg. Oncol.

38, 101564 (2021). https://doi.org/10.1016/j. suronc.2021.101564

59. M.H. Aref, I.H. Aboughaleb and Y.H. El-Sharkawy, "Tissue characterization utilizing hyperspectral imaging for liver thermal ablation", Photodiagnosis Photodyn. Ther. 31, 101899 (2020). https://doi. org/10.1016/j.pdpdt.2020.101899

60. M.H. Aref, I.H. Aboughaleb, M. Rabie and Y.H. El-Sharkawy, "Spatiotemporal thermal contours mapping of ex-vivo bovine liver radiofrequency thermal ablation utilizing hyperspectral image and its associated K-mean clustering algorithm", Biomed. Res. Clin. Rev. 1(1) (2020). https://www.auctoresonline. org/article/spatiotemporal-thermal-contours-mapping-of-ex-vivo-bovine-liver-radiofrequency-thermal-ablation-utilizing-hyperspectral-image-and-its-associated-k-mean-clustering-algorithm

61. P.C. Benias and D.L. Carr-Locke, "Principles of electrosurgery", ERCP 86-92.e1 (2019). https://doi. org/10.1016/B978-0-323-48109-0.00011-0

62. S.L. Van Es, "Digital pathology: semper ad meliora", Pathology 51(1), 1-10 (2019). https://doi. org/10.1016/j.pathol.2018.10.011

63. Breastcancer.org, Getting your Breast Cancer Pathology Report (2006). https://www.breastcancer. org/symptoms/diagnosis/getting_path_report
64. S. Ortega, M. Halicek, H. Fabelo, R. Camacho, M. de la Luz Plaza, F. Godtliebsen, G.M. Callicó and B. Fei, "Glioblastoma tumor cells in H\&E slides using convolutional neural networks", Sensors 20(7), 1-16 (2020). https://doi.org/10.3390/s20071911

65. T. Adão, J. Hruška, L. Pádua, J. Bessa, E. Peres, R. Morais and J.J. Sousa, "Hyperspectral imaging: a review on UAV-based sensors, data processing and applications for agriculture and forestry", Remote Sens. 9(11), 1110 (2017). https://doi.org/10.3390/ rs9111110

66. S.S.M. Noor, J. Ren, S. Marshall and K. Michael, "Hyperspectral image enhancement and mixture deep-learning classification of corneal epithelium injuries", Sensors 17(11), 2644 (2017). https://doi. org/10.3390/s17112644

67. A. Holmer, P. Wahl, M. Dau and P.W. Kämmerer, "Hyperspectral imaging in perfusion and wound diagnostics - methods and algorithms for the determination of tissue parameters", Biomed. Eng. 63(5), 547-556 (2018). https://doi.org/10.1515/bmt-2017$\underline{0155}$

68. M.B. Henriksen, Hyperspectral Imager Calibration and Image Correction. MSc Thesis, NTNU (2019). http:// hdl.handle.net/11250/2625737

69. V. Kumar and P. Gupta, "Importance of statistical measures in digital image processing", Int. J. Emerg. Technol. Adv. Eng. 2(8), 56-62 (2012).

70. W. Zhou and Y. Xie, "Interactive contour delineation and refinement in treatment planning of imageguided radiation therapy", J. Appl. Clin. Med. Phys. 15(1), 141-166 (2014). https://doi.org/10.1120/ jacmp.v15i1.4499

71. J. Malik, S. Belongie, T. Leung and J. Shi, "Contour and texture analysis for image segmentation", Int. J. Comput. Vis. 43, 7-27 (2001). https://doi. org/10.1023/A:1011174803800

72. P. Arbeláez, M. Maire, C. Fowlkes and J. Malik, "Contour detection and hierarchical image segmentation", IEEE Trans. Pattern Anal. Mach. Intell. 33(5), 898-916 (2011). https://doi.org/10.1109/ TPAMI.2010.161

73. K. Qin, K. Xu, F. Liu and D. Li, "Image segmentation based on histogram analysis utilizing the cloud model", Comput. Math. Appl. 62(7), 2824-2833 (2011). https://doi.org/10.1016/j. camwa.2011.07.048

74. H. Kaur and N. Sohi, "A study for applications of histogram in image enhancement", Int. J. Eng. Sci. 
6(6), 59-63 (2017). https://doi.org/10.9790/18130606015963

75. P.D.R. Raju and G. Neelima, "Image segmentation by using histogram thresholding", Int. J. Comput. Sci. Eng. Technol. 2(1), 776-779 (2012). http:// www.ijcset.net/docs/Volumes/volume2issue1/ijcset2012020103.pdf

76. H. Wu, L.R. Wilkins, N.P. Ziats, J.R. Haaga and A.A. Exner, "Real-time monitoring of radiofrequency ablation and postablation assessment: accuracy of contrast-enhanced US in experimental rat liver model", Radiology 270(1), 107-116 (2014). https:// doi.org/10.1148/radiol.13121999

77. P. Wiggermann, K. Brünn, J. Rennert, M. Loss, H. Wobser, A.G. Schreyer, C. Stroszczynski and E.M. Jung, "Monitoring during hepatic radiofrequency ablation (RFA): comparison of real-time ultrasound elastography (RTE) and contrast-enhanced ultrasound (CEUS): First clinical results of 25 patients", Ultraschall Med. 34(6), 590-594 (2013). https://doi. org/10.1055/s-0033-1355820

78. Y.Z. Zhang, T. Xu, H.Y. Gong, C.Y. Li, X.H. Ye, H.J. Lin, M.P. Shen, Y. Duan, T. Yang and X.H. Wu, "Application of high-resolution ultrasound, real-time elastography, and contrast-enhanced ultrasound in differentiating solid thyroid nodules", Medicine 95(45), e5329 (2016). https://doi.org/10.1097/ MD.0000000000005329

79. S. Swierczynski, F. Primavesi, E. Klieser, T. Kiesslich, T. Jäger, R. Illig, D. Neureiter, D. Ofner and S. Stättner, "382. Thermographic monitoring of radiofrequency and microwave ablation in a perfused porcine liver model", Eur. J. Surg. Oncol. 40(11), S147 (2014). https://doi.org/10.1016/j.ejso.2014.08.372

\section{Appendix}

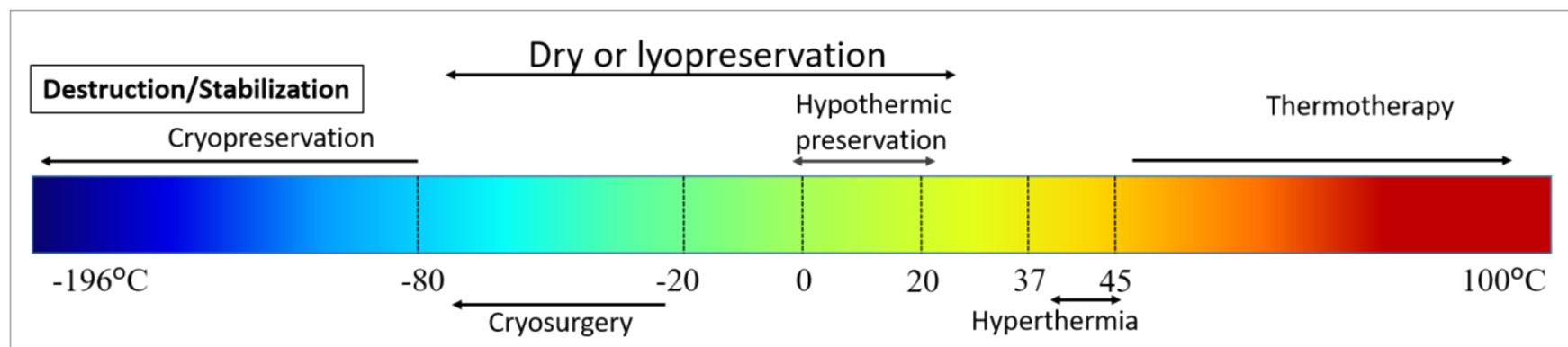

Figure A1. An overview of typical thermal effects on the thermostability of biological systems over a wide temperature range (from the cryogenic to hyperthermic temperatures).

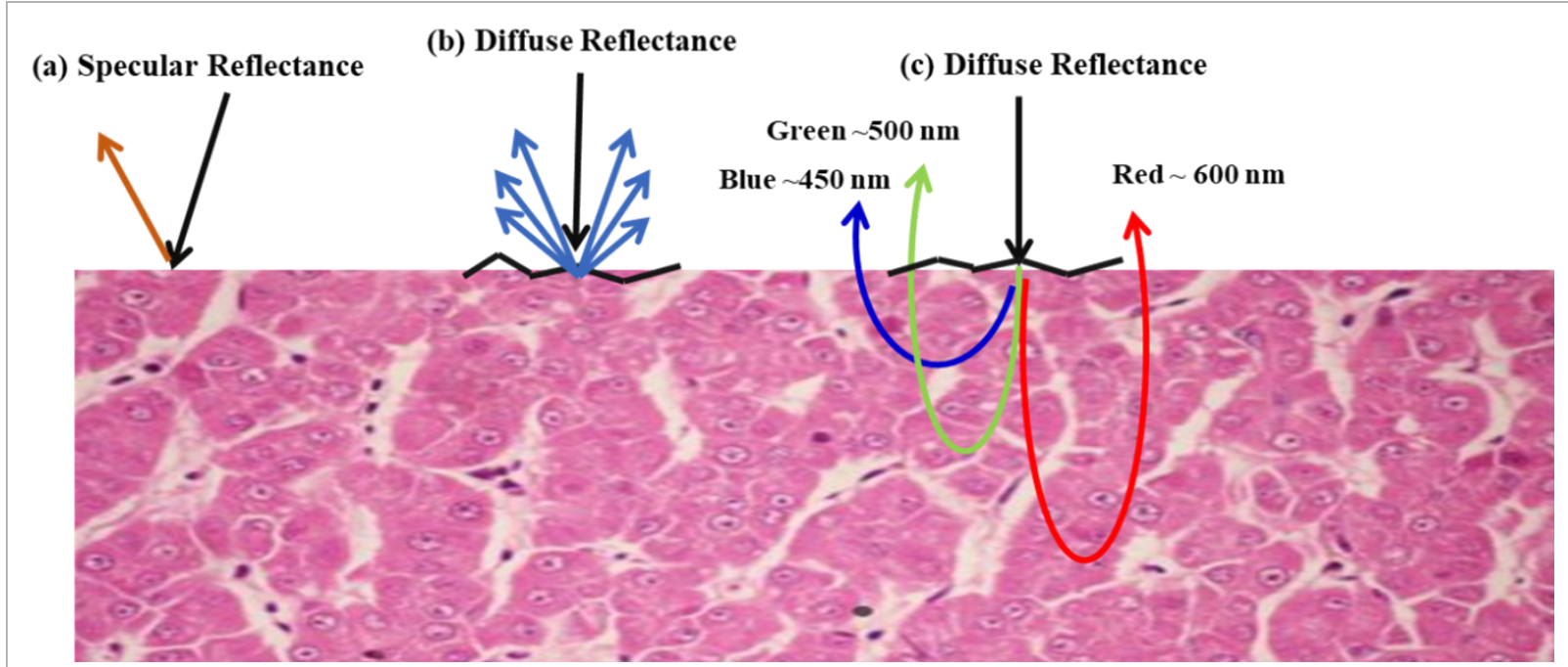

Figure A2. Some of the light interaction with the ex vivo bovine liver tissue sample. (a) Specular reflectance at a smooth surface; (b) diffuse reflection from an irregular surface without any absorption; (c) diffuse reflection from an irregular surface with absorption at different wavelengths. 


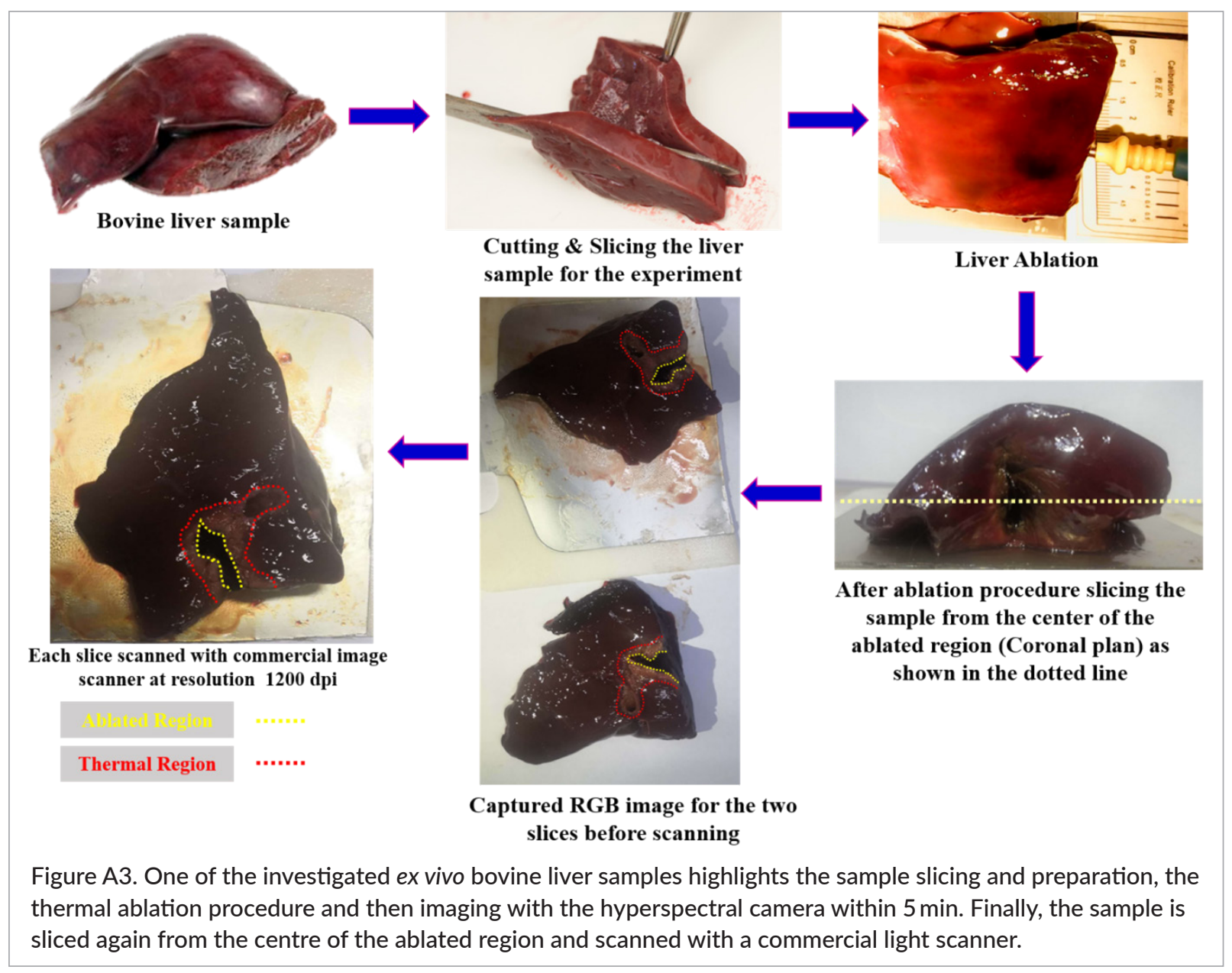




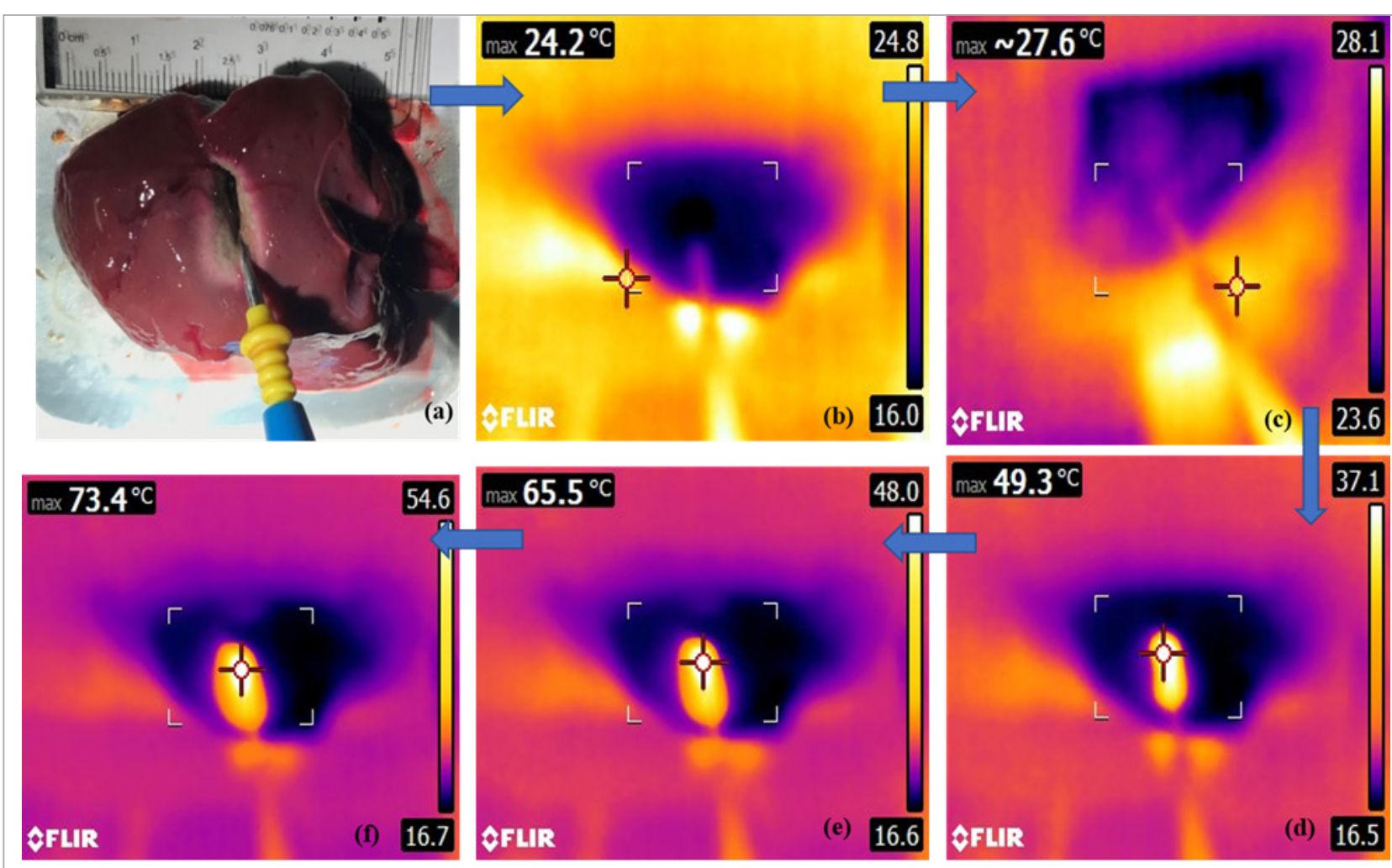

Figure A4. The investigated ex vivo sample with the measurements from the thermal camera for the surface thermal ablation procedure to characterise the spectral signatures of the various regions (ablated, normal, thermally affected region). (a) The captured RGB image of the investigated ex vivo sample after ablation. (b-d) The temperature recording by the thermal camera (FLIR, ETS 320 , USA) from the initial temperature $\left(24^{\circ} \mathrm{C}\right.$ ) to $73.4^{\circ} \mathrm{C}$ was measured manually from the start of the experiment approximately every $10 \mathrm{~s}$ until the end of the experiment.

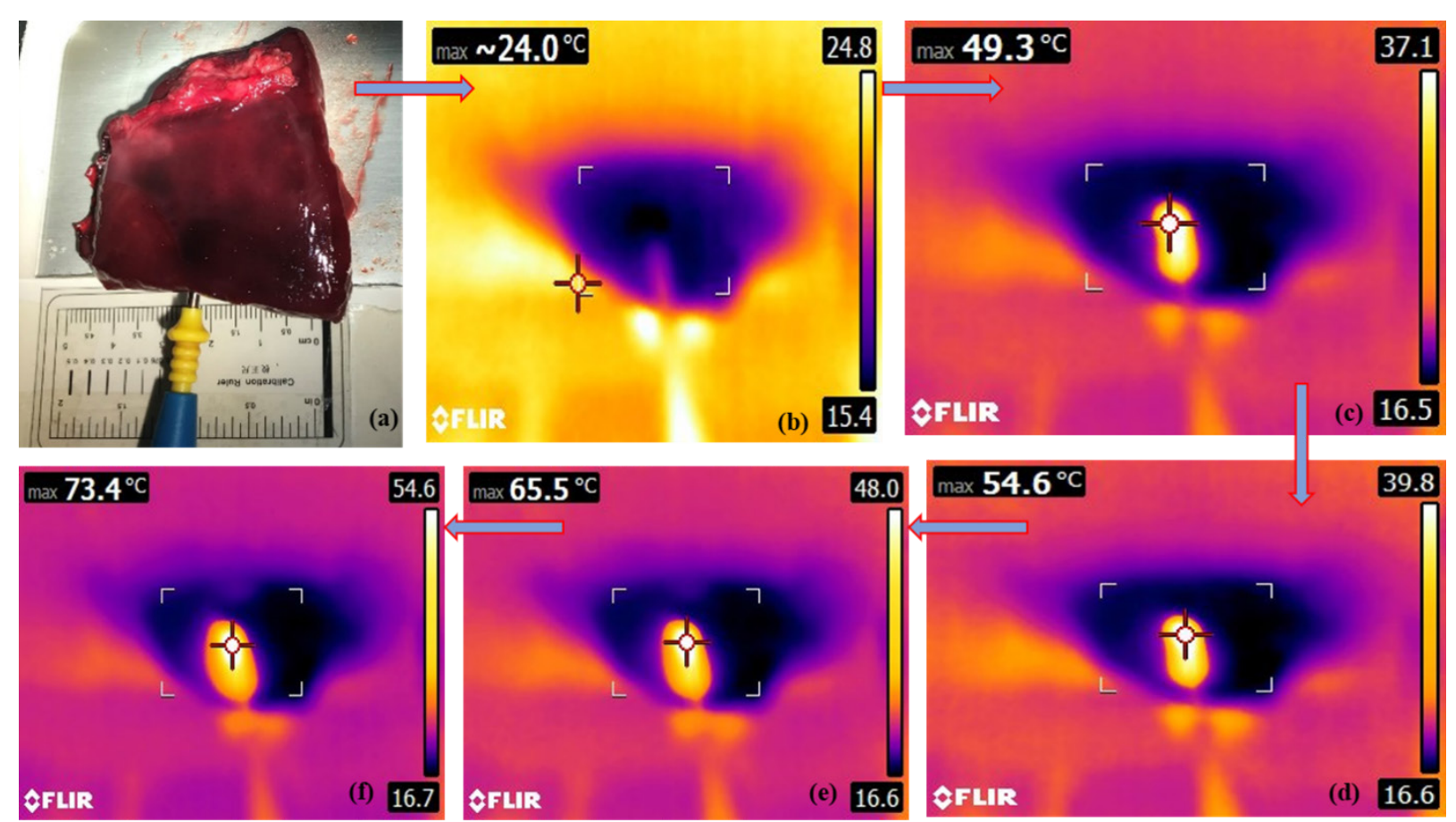

Figure A5. The investigated ex vivo sample with the measurements from the thermal camera for the side-penetration thermal ablation procedure to identify various non-visual regions (ablated, normal, thermally affected region). (a) The captured RGB image of the ex vivo sample after ablation; (b-d) temperature recording using the thermal camera (FLIR, ETS 320 , USA) from the initial temperature $\left(24^{\circ} \mathrm{C}\right)$ to $73.4^{\circ} \mathrm{C}$ was manually measured from the start of the experiment approximately every $10 \mathrm{~s}$ until the end of the experiment. 

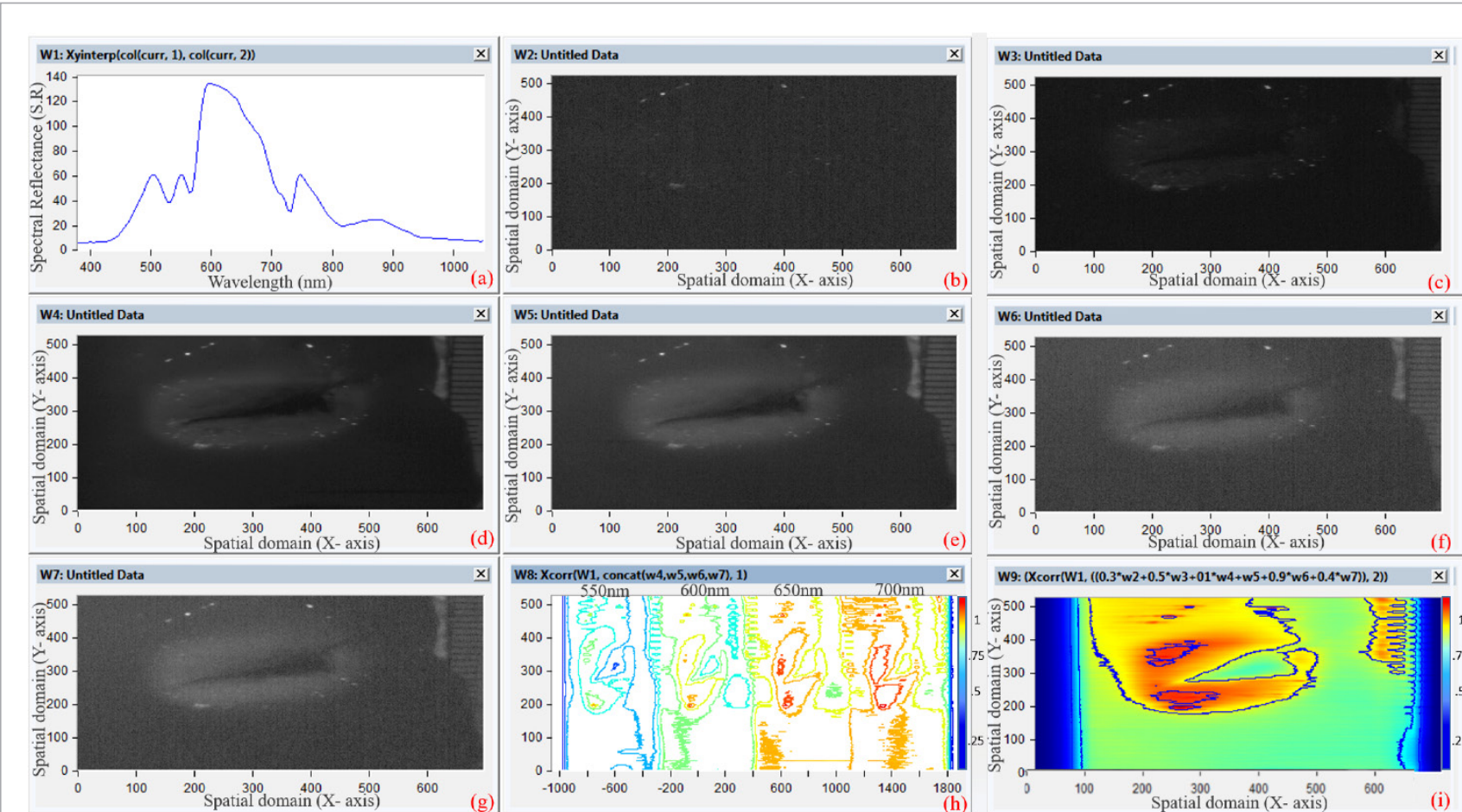

W9: (Xcorr(W1, $\left.\left.\left(\left(0.3^{*} w 2+0.5^{*} w^{*}+01^{*} w 4+w 5+0.9^{*} w 6+0.4^{*} w 7\right)\right), 2\right)\right) \quad \underline{X}$ ]

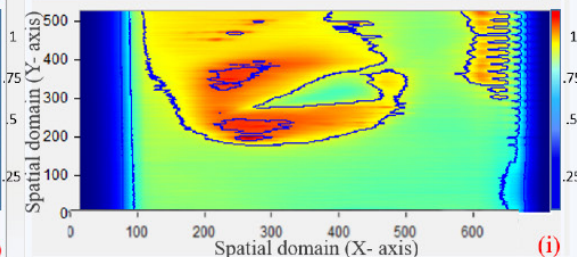

Figure A6. The custom image processing for the HSI of the ex vivo liver sample after surface thermal ablation. (a) The reflected light spectrum from the whiteboard reference. Spectral images at (b) $450 \mathrm{~nm}$, (c) $500 \mathrm{~nm}$, (d) $550 \mathrm{~nm}$, (e) $600 \mathrm{~nm}$, (f) $650 \mathrm{~nm}$ and (g) $700 \mathrm{~nm}$. (h) Contour delineation of the correlated spectral images with the reference which identified the various regions in the sample (normal, ablated, thermally affected regions) at 550, 600, 650 and 700 nm). (i) Overlay of the contour mapping for the superimposed HS images at 550, 600, 650 and $700 \mathrm{~nm}$ to distinguish the thermal and ablation regions. 

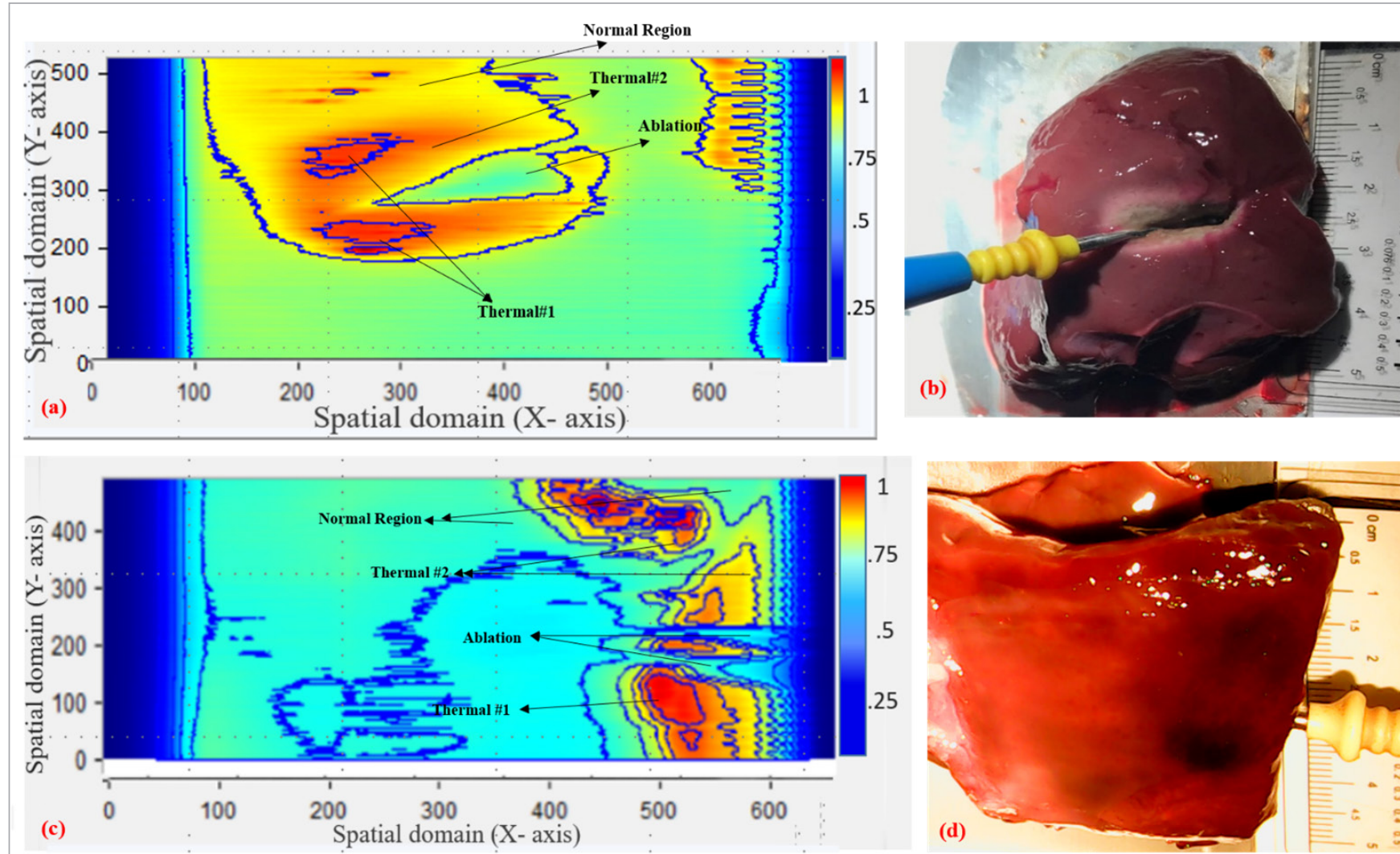

Figure A7. (a) The superimposed image of the surface RFA of the investigated ex vivo liver sample for the spectral images at $550,600,650$ and $700 \mathrm{~nm}$, where we could identify the various regions: the normal region in yellow, the ablated in cyan, the highly thermally affected (Thermal \#1) in dark orange and identified with the blue contour region, and the low thermally affected (Thermal \#2) in light orange. (b) The captured image of the surface RFA of the investigated ex vivo liver sample. (c) The superimposed image of side-penetration RFA of the investigated ex vivo liver sample for the spectral images at 550, 600, 650 and $700 \mathrm{~nm}$, where we could identify the various regions: the normal region in light green (cyan), the ablated region in light blue, highly thermally affected (Thermal \#1) in dark orange and the low thermally affected (Thermal \#2) in yellow-light orange]. (d) The captured image of the side-penetration RFA of the investigated ex vivo liver sample. 

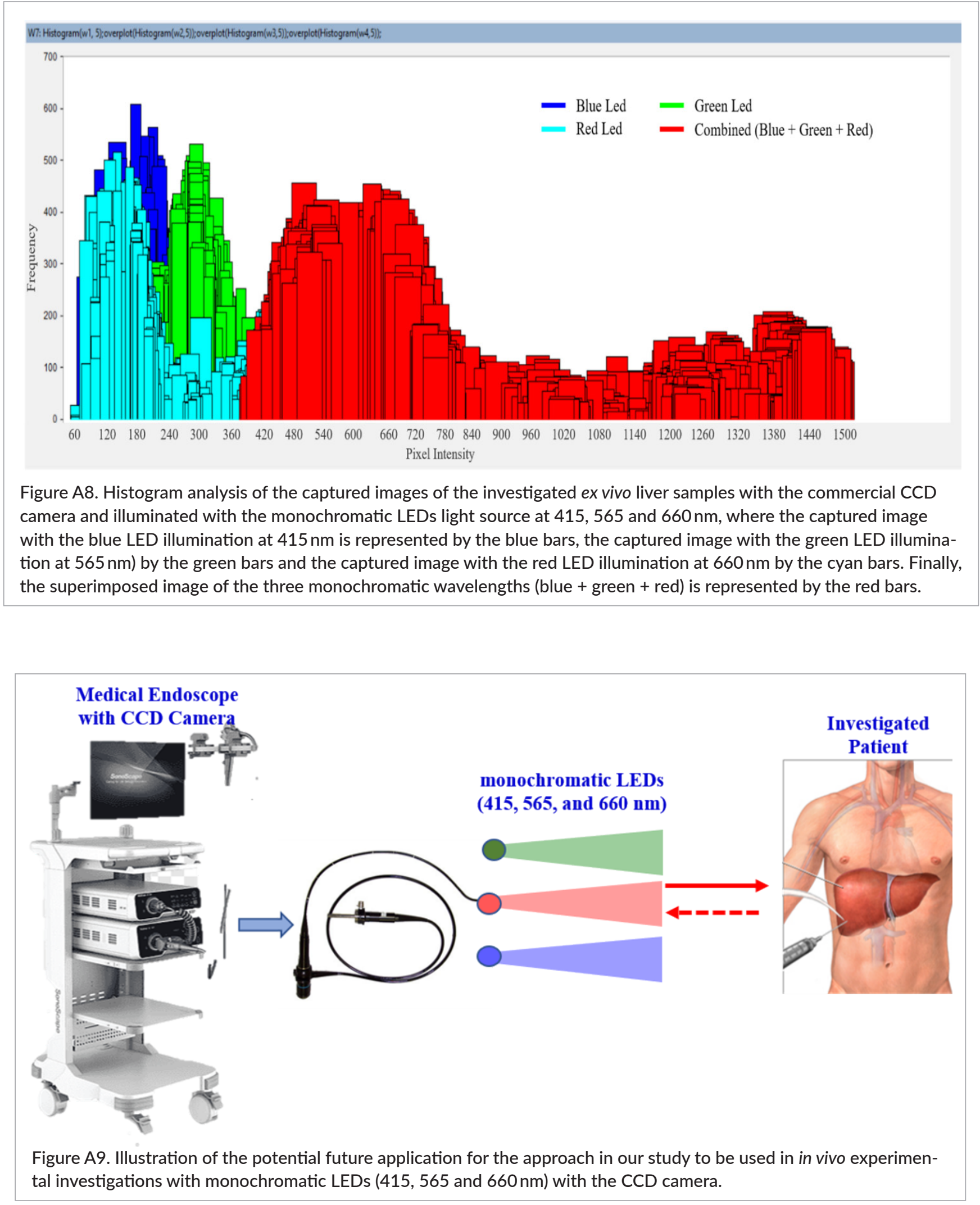